\title{
Intra-household Resource Allocation and Familial Ties*
}

\author{
Harounan Kazianga $^{\dagger}$ and Zaki Wahhaj $j^{\ddagger}$ \\ Oklahoma State University and University of Kent
}

September 2016

\begin{abstract}
In this paper, we investigate the link between intra-household resource allocation and familial ties between household members. We show that, within the same geographic, economic and social environments, households where members have 'stronger' familial ties (nuclear family households) achieve near Pareto efficient allocation of productive resources and Pareto efficient allocation of consumption while households with 'weaker' familial ties (extended family households) do not. We propose a theoretical model of the household based on the idea that altruism between household members vary with familial ties which generates predictions consistent with the observed empirical patterns.
\end{abstract}

Keywords: Intra-household Allocation, Social Norms, Extended Families, Altruism, Household Farms, Income Shocks, Risk-sharing, Consumption Smoothing

JEL Codes: O12, D13, Q1

${ }^{*}$ We thank the Direction de la Prospective et des Statistiques Agricoles et Alimentaires (DPSAA) from the Ministry of Agriculture of Burkina Faso for the sharing their data with us.

${ }^{\dagger}$ Email: harounan.kazianga@okstate.edu. Address: 324 Business Building, Spears School of Business, Oklahoma State University, Stillwater, OK 74078, USA

${ }^{\ddagger}$ Email: z.wahhaj@kent.ac.uk. Address: School of Economics, Keynes College, University of Kent, Canterbury CT2 7NP, United Kingdom. 


\section{Introduction}

The question as to how resources are allocated within households has long been of interest to economists. Particularly in societies where state support and market institutions are weak, the household remains an important unit of production, and investment in the human capital of children.

The two models of intra-household allocation that have received the most attention in the literature and tested most frequently using household data are the unitary and the collective household models. The unitary model, which assumes that the household acts as a single decision unit maximizing a common utility function, has been consistently rejected by empirical evidence (reviewed by Haddad, Hoddinott and Alderman 1997, Doss 2013). In contrast to the unitary model, the collective model allows the representation of individual behavior within the household. Chiappori $(1988,1992)$ has shown that simply assuming Pareto efficient allocations implies a set of testable restrictions. The basic model has been extended in several directions, including household production (e.g. Udry 1996) and children (e.g. Thomas 1990), among others.

The empirical tests of the collective household model, however, have been less consistent than those of the unitary household model. Attanasio and Lechene (2014), Bobonis (2009), Browning, Bourguignon, Chiappori and Lechene (1994), Browning and Chiappori (1998), Chiappori, Fortin and Lacroix (2002) and Rangel and Thomas (2005), among others, fail to reject Pareto efficiency of intrahousehold resource allocations in various contexts. On the other hand, Dercon and Krishnan (2000), Duflo and Udry (2004), Goldstein and Udry (2008), and Udry (1996) reject efficient intrahousehold resource allocations. A broad pattern emerges, however, from these seemingly conflicting empirical results. On the one hand, the studies that reject Pareto efficiency are concentrated in Africa and have tended to focus on household productive resources (e.g. Udry, 1996; Goldstein and Udry, 2008; Kazianga and Wahhaj, 2013; Guirkinger et al., 2015). On the other hand, studies that fail to reject efficiency tend to focus on consumption in developing countries (e.g. Bobonis, 2009; Attanasio and Lechene, 2014) or labour supply in developed countries.

It has been widely noted that a key element of interactions within a household is their repeated and regular nature. Game theoretic reasoning implies that individuals who expect to interact repeatedly into the future should be able to sustain greater levels of cooperation compared to those who interact sporadically. If household members care about future outcomes sufficiently, then they will be able to achieve efficiency in consumption and production decisions (Browning and Chiappori, 1988; Udry 1996; Duflo and Udry, 2004). This reasoning would apply to all individuals living under the 'same roof', whatever the nature of familial or kinship ties between them.

However, if cooperation between household members are sustained through altruism, or norms of familial rights and obligations, then households with different types of familial composition may well diverge in their behaviour. For example, if individuals exhibit higher levels of altruism towards

members of their nuclear family unit, then nuclear family households may be able to achieve more 
efficient outcomes than households consisting of extended family members or unrelated individuals.

Despite a growing literature, there remain significant gaps in our understanding of the role of extended families and kinship networks in economic interactions (see Cox and Fafchamps 2008 for a review; and di Falco and Bulte (2011, 2013), Baland et al. (2013) for recent work on sub-Saharan Africa). Furthermore, this literature is largely focused on extended family members who inhabit separate households but not on cohabiting members of the same extended family. By contrast, there is scarce evidence on whether or how family ties affect intra-household allocation.

In this paper, we contribute to the literature on intra-household allocation and the role of familial ties in economic outcomes in two ways. First, we show, within the same geographic, economic and social environments, that - conditional on the co-residence decision - individuals with 'stronger' familial ties achieve near Pareto efficient allocation of productive resources and Pareto efficient allocation of consumption within the household while individuals with 'weaker' familial ties do not. Thus, we are able to reconcile two strands of empirical evidence in the literature that have either failed to reject or have rejected Pareto efficient allocation of household resources. This is in line with early research by Lundberg (1988) who attempted to relate labour supply of husbands and wives in the US labour market to the household structure. She found evidence that husbands and wives without pre-school children behaved like separate individuals in determining their labour supply, while families with young children appeared to determine labour supply jointly. More recently, Angelucci and Garlick (2015) found evidence of Pareto efficient consumption allocation for households with relatively old heads but not for households with relatively young heads.

Second, we develop a theoretical model where we explicitly link the household decision-making process to the nature of familial ties within the household and account for the observed differences in efficiency between household with 'stronger' familial ties and those with 'weaker' familial ties. In the rest of the paper, we refer to households with 'stronger' familial ties as 'nuclear' family households; i.e. households consisting of the head, his spouse or spouses and their children, and we refer to households with 'weaker' familial ties as extended family households, i.e. households that include at least one member in addition to the nuclear unit.

The setting for the empirical analysis in this paper is rural Burkina Faso. Agricultural households in Burkina Faso provide an interesting setting for exploring the topic because of the diversity of family ties that exist within the same household (discussed in Section 4) and the practice of assigning farm plots, individually, to adult household members for which they control production choices, as well as the proceeds of farm output (Udry 1996). Besides these 'private' plots, the household farms on one or more 'collective' plots, under the management of the household head (Kazianga and Wahhaj, 2013). According to a social norm, each able household member is expected to contribute some labour to the 'collective farm' and the head is expected to use its proceeds for expenditures on household public goods (Hammond 1966; Fiske 1991; Lallemand 1977).

We find that, controlling for plot characteristics and household-crop-year fixed-effects, collective plots use labour more intensively and achieve higher agricultural yields than private plots. Using 
the test of efficiency in agricultural production based on the approach pioneered by Udry (1996), we are able to reject the hypothesis of efficiency in production for both extended family households and nuclear family households. However, (i) yields achieved on private plots in nuclear family households are close to those achieved on collectively farmed plots while the corresponding gaps in extended family households are significantly larger. Using data on consumption expenditures by different household members, we implement two tests of intra-household risk-sharing, based data on (ii) food consumption expenditures and idiosyncratic shocks to household income, following Duflo and Udry (2004) and (iii) child anthropometrics and shocks to mothers' farm income. With both approaches, we are able to reject the hypothesis of efficient risk-sharing for extended family households but not for nuclear family households.

Our data-set on agricultural resource allocation allows us to examine which household members are providing labour on which farm plots and, thus, the role of familial ties in labour allocation. We find that (iv) household members who share a nuclear family tie provide more labour on each other's private farm plots, as compared to household members who share an extended family tie, or no family ties; (v) for a given relation to the household head, household members provide more labour on collective farm plots in nuclear family households than in extended family households, controlling for individual and plot characteristics and household-year fixed-effects.

To explain these empirical patterns, we propose a model of household decision-making in which nuclear family members exhibit greater altruism towards each other, or a greater alignment of preferences, compared to a pair of individuals who are unrelated or are connected by extendedfamily ties. This assumption can be motivated by the evolutionary approach to altruism and familial ties, based on the work of Hamilton (1964), as discussed in Cox and Fafchamps (2008). Then, labour contributions and transfers that nuclear family members make to each other voluntarily (more precisely a subgame perfect equilibrium) may be sufficient to achieve efficiency in production and consumption decisions within a nuclear family household. In the case of the extended family household, such voluntary contributions may be insufficient to achieve the first-best. But the existence of the social norm described above enables the household head to commit to using the output of the collective farm for the well-being of the entire household. This leads to a distortion of productive resources in favour of the collective farm but enables the household to achieve a second-best allocation.

If nuclear family households are able to allocate resources more efficiently, it raises the question why do extended family households exist at all? To this question, we are able to provide two types of answers based on the available data. First, in a setting where labour markets function poorly or are non-existent, co-habitation can provide the basis of labour exchange (Berry 1993), allowing more effective monitoring of labour by the head, as well as the remuneration in the form of private plots and provision of household public goods. Second, in the absence of formal insurance and lack of effective risk-sharing arrangements between households, an additional member allows greater income diversification and improves the ability of the household to engage in consumption 
smoothing. The addition of a extended-family member or unrelated individual to the household may reduce efficiency but would nevertheless increase net welfare if these benefits are sufficiently high. Consistent with these hypotheses, we find that (vi) households where the head has more inherited land, and consequently the marginal product of labour is higher, is more likely to include the co-residence of extended family members and unrelated individuals; (vii) household heads exposed to greater income volatility due to the characteristics of their inherited land and local rainfall conditions are more likely to end up with extended-family households; (viii) household food consumption is more sensitive to shocks to agricultural income in the case of nuclear family households than in the case of extended family households.

Extended family households, on average, have more members; and a head who is more likely to by polygynous and, on average, older. To investigate whether the differences in resource allocation between the two groups of households are due to these observed differences, we replicate the tests of efficiency in production and consumption for subsamples in which nuclear and extended family households are identical or similar along these dimensions. The pattern of results described above persists for these subsamples.

It is important to recognise that the individuals in our data are self-selecting into different household structures, and this selection process may itself contribute to differences in efficiency between nuclear and extended family households. For example, if individuals more skilled at cooperation self-select into nuclear family households, this could also generate the observed patterns in consumption efficiency, and farm yields and labour use intensity across farm plots. (It would not explain, however, our results regarding individual labour contributions - described in (iv) above where we compare across different familial ties within extended family households only). Therefore, strictly speaking, the differences in intra-household allocation between nuclear and extended family households we report in the paper include both the direct effects of familial ties and the potential selection effects. Nevertheless, we put forward the theory on family ties and altruism as a parsimonious explanation for the combined evidence regarding labour use across farm plots, plot yields and consumption risk-sharing as described in (i)-(v) above.

Foster and Rosenzweig (2002) develop and test a theory of household division using Indian village data, in which preference heterogeneity among household members also plays an important role. Specifically, since household public goods must, by definition, be consumed in the same quantity by families residing in 'joint households', those who have different preferences regarding private and household public goods have incentives to break away and form a household unit on its own. However, Foster and Rosenzweig (2002) assume that the allocation of resources within the joint household is efficient, and do not investigate whether and how family ties affect resource allocation within the joint household. By contrast, given the large body of evidence pointing to an inefficient allocation of resources within agricultural households in sub-Saharan Africa, we posit that the intra-household allocation of resources is a subgame perfect equilibrium and estimate the level of altruism (or alignment of preferences) between household members using data on labour 
allocation across farm plots.

Guirkinger and Platteau (2014) develop a theory to explain both household division and individualisation of farm plots for agricultural households in West Africa, using the idea of 'moral hazard in teams' in collective farm work. While a similar mechanism may be at work for our sample of households in Burkina Faso, it would not explain why collective farm plots achieve higher yields than private farm plots. In particular, the distribution of plot yields across farm plots within the same household correspond closely to the distribution of labour for our sample; and therefore, we analyse the data within a theoretical framework which can account for the labour allocation choices.

The remainder of the paper is organised as follows. In the next section, we describe the evolution of household structure in West Africa during the last twenty years using household-level data and discuss possible reasons for these changes. The theoretical framework is developed in Section 3 . The data used in our analysis is described in Section 4. Section 5 investigates plot yields and allocation of labour across different types of farm plots managed by the same household and compares the dispersion in yields across different types of households. We implement tests of efficient risk-sharing using food consumption and child anthropometrics data in Section 6. Alternative explanations for the pattern of results are explored in Section 7 and alternative theories are discussed in Section 8. In Section 9, we discuss possible explanations for the presence of extended-family households in West Africa, and provide evidence regarding these explanations. Section 10 concludes.

\section{Evolution of Household Composition in West Africa}

We define a nuclear family household as one that consists only of the household head, his wife or wives and their children. Extended family households would include at least one individual who does not belong to the household head's nuclear family. In the African context, a household may be composed of one or more 'cooking units', embedded within a 'farming group' (i.e. a group of individuals who farm together) and a dwelling group (Goody, 1989).

Extended family households can arise from married sons or siblings who decide to raise their own families within their father's or brother's household and from other adult relatives who decide to join the households (see, for example, Coulson, 1962; Adepoju, 2005; Young and Ansell, 2008). Child-fostering, a practice which is widely observed in sub-Saharan Africa, would also lead to extended family households according to our definition (Akresh 2009).

Widespread market failure in rural labour markets means that family or household members are, commonly, the main source of farm labour for small-holder agricultural households in subSaharan Africa. This has historically provided an impetus for the cohabitation of individuals who do not belong to the same nuclear family (Berry 1993).

Rising land pressures, it has been argued, are one of the key drivers behind the individualisation of land tenure which, in turn, can cause agricultural households to split up into smaller farming units (see, for example, Guirkinger and Platteau 2014 and the references within). The same pressures, 
coupled with the growth of income-earning opportunities outside of agriculture would make it more difficult for agricultural households to hold on to its working members with the promise of land assets or future claims on the earnings generated by these assets. To the extent that there are stronger ties between members of a nuclear family than between members of the extended family and unrelated individuals, these pressures can lead to an evolution of agricultural households towards the nuclear family model.

The Demographic and Health Surveys (DHS), which provides data on household composition across countries in different years using consistent definitions, allow us to examine how the prevalence of nuclear family households is evolving over time. Looking at the 9 countries in West Africa which had three or more DHS surveys by September 2014 - Benin, Burkina Faso, Cote d'Ivoire, Ghana, Guinea, Mali, Niger, Nigeria and Senegal - we find that the share of nuclear family households rose in 5 of them during the period 1993-2013. It has remained stable in 3 countries and has declined in one country (Ghana). The multiplication of urban households, by itself, cannot account for these changes; the pattern persists when we restrict the analysis to the rural subsample 11

It is important to recognise that the evolution towards the nuclear family model does not imply a weakening of the extended family network or kinship-based ties. Indeed, there is a large literature emphasizing the important role that these networks continue to play in economic affairs in subSaharan Africa (for recent studies on the subject, see, for example, di Falco and Bulte (2011, 2013); Baland et al. (2013)).

Besides a potential long-term trend towards nuclear family households, household composition may be affected by the periodic migration of individual members as a way of coping with income seasonality and weather-related shocks such as droughts (Findley 1994; Cordell et al., 1996; Henry et al. 2004). Thus, the cohabitation of extended family members and unrelated individuals may be a recurring and persistent phenomenon. More generally, it is important to recognise that whether, at any point in time, a household is composed of a nuclear family unit or not is endogenous to the migration decisions of its members and, thus, nuclear and extended family households can potentially differ in terms of their members' preferences, endowments and past shocks. While we do not account for this explicitly in our theoretical modelling and empirical analysis, our interpretation of the observed differences in intra-household allocation between nuclear and extended-family households need to be informed by these potential selection effects.

\section{Theoretical Framework: Intra-household Allocation of Land, Labour and Consumption Expenditures}

Consider a household consisting of $n$ adult members represented by the set $\mathcal{I}=\{1,2, ., n\}$. The household has total farm land of area $A$ and average quality $q$ which is to be allocated among the different household members and, potentially, a 'collective' plot. Each household member $i$ has a

\footnotetext{
${ }^{1}$ See Table 1 in Kazianga and Wahhaj (2016).
} 
time endowment of $E^{i}$ which he or she would allocate to labour across the different farm plots after the land has been divided up. There is no agricultural labour market and therefore all plots must be farmed using household labour.

We denote by $A_{j}, q_{j}$ the size and quality, respectively, of household plot $j \in\{1, . ., n, c\}$. Here, $j=c$ denotes a collective plot, and $j \in \mathcal{I}$ represents the private plot assigned to household member $j$. We denote by $L_{m j}$ and $L_{f j}$ the total amounts of male and female labour, respectively, allocated to plot $j$. We assume, for simplicity, that the crop grown and the agricultural technology employed, is the same across all plots. Agricultural output from plot $j$ is given by $y_{j}=F\left(q_{j}, A_{j}, L_{m j}, L_{f j}, \mathbf{r}\right)$ where $F($.$) is a Cobb-Douglas production function:$

$$
F\left(q_{j}, A_{j}, L_{m j}, L_{f j}, \mathbf{r}\right)=R\left(q_{j}, \mathbf{r}\right)\left(A_{j}\right)^{\alpha}\left(L_{m j}\right)^{\beta_{1}}\left(L_{f j}\right)^{\beta_{2}} \text { for } j \in\{1, . ., n, c\}
$$

and $\mathbf{r}$ is a stochastic vector of relevant measures of rainfall. The function $R($.$) allows the effect of$ rainfall on output to, potentially, vary according to land quality. Let $\mathbf{y}=\left(y_{1}, . ., y_{n}, y_{c}\right)$ denote the income levels of the household from its different agricultural plots. The proceeds from the farms can be spent on private goods or a household public good. We denote by $z$ total expenditures on the household public good and by $x_{i p}$ total expenditures on private good $p$ consumed by household member $i$. We use a CES utility function to represent preferences as follows:

$$
U^{i}\left(\mathbf{x}_{1}, . ., \mathbf{x}_{n}, z ; \boldsymbol{\delta}_{i}\right)=\left[v\left(\mathbf{x}_{i}\right)+\delta_{i c}(z)^{\rho}+\sum_{j \neq i} \delta_{i j} v\left(\mathbf{x}_{j}\right)\right]^{\frac{1}{\rho}} \text { for } i \in \mathcal{I}
$$

where $\boldsymbol{\delta}_{i}=\left(\delta_{i 1}, . ., \delta_{i n}, \delta_{i c}\right), \mathbf{x}_{i}=\left(x_{i 1}, . ., x_{i \bar{p}}\right)$, and $v\left(\mathbf{x}_{i}\right)=\sum_{p=1}^{\bar{p}} \delta_{p v}\left(x_{i p}\right)^{\rho}{ }^{2}{ }^{2}$ The parameters $\delta_{i j}, \delta_{j i} \in[0,1]$ capture the level of altruism between household members $i$ and $j$ and $\delta_{i c}, \delta_{j c}$ their relative preferences for household public goods. If $\delta_{i j}=\delta_{j i}=0$, then household members $i$ and $j$ do not care at all about each other's private consumption. On the other hand, if If $\delta_{i j}=\delta_{j i}=1$ and $\delta_{i c}=\delta_{j c}$, then their preferences are perfectly aligned.

A full description of intra-household resource allocation should specify how the household's land is divided between its farm plots, which we represent by the vectors $\mathbf{A}=\left(A_{c}, A_{1}, . ., A_{n}\right)$, and $\mathbf{q}=\left(q_{c}, q_{1}, . ., q_{n}\right)$; the labour contribution by each household member $i$ across these farm plots, represented by $\mathbf{L}^{i}=\left(L_{c}^{i}, L_{1}^{i}, . ., L_{n}^{i}\right)$; and expenditures on the household public good $z$ and private goods $\left(\mathbf{x}_{1}, . ., \mathbf{x}_{n}\right)$. The Collective Household Model implies efficiency in household production choices and perfect risk-sharing in consumption choices. The existing literature provides econometric tests of these hypotheses (Udry 1996; Duflo and Udry, 2004) which we implement in Sections 5 and 6 respectively. In the following section, we develop an alternative model where decisions are made in a non-cooperative manner - i.e. there is no binding agreement regarding intra-household allocation.

\footnotetext{
${ }^{2}$ Note that we abstract away from leisure in modelling preferences. Introducing leisure has no implications for our theoretical results on labour and consumption as long as leisure is additively separable from other consumption goods in the utility function. Therefore, for ease of exposition, we ignore leisure in the following presentation.
} 


\subsection{Non-Cooperative Decision-Making between Altruistic Household Members}

We assume the following timing of events and decisions during an agricultural season: (1) household composition is determined - i.e. existing household members may opt to leave and new individuals may join it - prior to the onset of the agricultural season; (2) the household head divides up the available land among members of the household and, potentially, a collective plot; (3) rainfall for the agricultural season is realised; (4) household members choose their labour contributions across farm plots; (5) output on each farm plot is realised and household members decide how to spend the proceeds from their private plots; the head decides how to spend the proceeds from the collective plot.

Rainfall patterns can potentially affect migration from rural households - and thus their composition - but the literature suggests that this is more likely to occur following harvest and before the start of planting for a new season - i.e. the period when there is limited demand for agricultural labour from the household (Findley 1994; Cordell et al., 1996; Henry et al. 2004) $!^{3}$ Our main analysis focuses on agricultural labour and consumption decisions. Therefore, based on the reasoning above, we take household composition as being fixed by the start of the agricultural season, and investigate the role of family ties, if any, on the subsequent allocation of labour and consumption within the household. We discuss the long-term determinants of household composition in Section 9.

Following the ethnographic literature, we assume that there is a social norm that prescribes that the proceeds from the collective plot be spent on household public goods 4 The norm can potentially incentivise other household members to provide labour on the collective plot (in the knowledge that they wil derive some utility from its proceeds). Modelling the social norm is not essential for deriving the key predictions of the model but it simplifies the analysis. Furthermore, it provides a rationale for the presence of collective plots, which are widely prevalent in the study area (see Section 4). We assume that violating the social norm can have costly social consequences and, therefore, the head always acts according to the norm. Thus, we have $z \geq y_{c}$.

Each household member $i$ has a reservation utility which they can obtain if they exit the household. Therefore, for other members remain within the household, the head has to ensure that each is able to attain at least his or her reservation utility in expectation from the intra-household allocation of land, and subsequent labour and consumption choices within the household. The head cannot commit ex-ante (i.e. before production takes place) to making private transfers from any farm plots over which he retains control. We assume that household members' production and consumption choices constitute a subgame perfect Nash equilibrium, which we solve for using backward induction.

\footnotetext{
${ }^{3}$ It is possible that migration can occur, and affect household composition, even during the agricultural season in drought years, but our analysis is based on data from surveys conducted in 2010-12 which were not subject to such extreme weather events.

${ }^{4}$ See references in the introduction and the discussion in Kazianga and Wahhaj (2013).
} 
Given a vector of realised incomes $\mathbf{y}$, the consumer optimisation problem for a household member $i$ can be written as

$$
\max _{z, \mathbf{x}_{i}} U^{i}\left(\mathbf{x}_{1}, . ., \mathbf{x}_{n}, z ; \boldsymbol{\delta}_{i}\right) \text { subject to } z+\sum_{p=1}^{\bar{p}} x_{i p} \leq z_{-i}+y_{i}, z \geq z_{-i}
$$

where $z_{-i}$ equals sum of expenditures on the household public good by all other household members. It can be shown that if, in equilibrium, a subset of household members $\mathcal{I}_{z} \subset \mathcal{I}$ make positive contributions to the household public good using the proceeds of their private plots, then

$$
z=\left(\Lambda^{-1}\right) \bar{y}_{z} \text { and } x_{j p}=\zeta_{j p c}\left(\Lambda^{-1}\right) \bar{y}_{z} \text { for each } j \in \mathcal{I}_{z}, p=1,2, . ., \bar{p}
$$

where $\bar{y}_{z}=y_{c}+\sum_{j \in \mathcal{I}_{z}} y_{j}$ and $\Lambda, \zeta_{j p c}$ are constants ${ }^{5}$ In other words, the resources of household members in $\mathcal{I}_{z}$ are pooled together although their expenditure decisions are made in a non-cooperative manner. This is akin to the 'income neutrality' result obtained by Bergstrom, Blume and Varian (1986) when investigating the private provision of public goods. For the remaining household members $j \in \mathcal{I}-\mathcal{I}_{z}$, we have $x_{j p}=\zeta_{p v}\left(\Lambda_{v}\right)^{-1} y_{j}$ where $\Lambda_{v}, \zeta_{p v}$ are constants ${ }^{6}$ We denote by $z(\mathbf{y})$ and $x_{i p}(\mathbf{y}), i \in \mathcal{I}, p=1,2, . ., \bar{p}$, the household's expenditures on different goods as a function of its income from the different household plots, and let $\mathbf{x}_{i}(\mathbf{y})=\left(x_{i 1}(\mathbf{y}), . ., x_{i \bar{p}}(\mathbf{y})\right)$.

Labour Use Intensity: Given an intra-household distribution of land A, q and level of rainfall r. we can write the labour optimisation problem for a household member $i$ as follows:

$$
\max _{\mathbf{L}^{i}} U^{i}\left(\mathbf{x}_{1}(\mathbf{y}), . ., \mathbf{x}_{n}(\mathbf{y}), z(\mathbf{y}) ; \boldsymbol{\delta}_{i}\right)
$$

subject to

$$
\begin{aligned}
y_{j} & =F\left(q_{j}, A_{j}, L_{m j}, L_{f j}, \mathbf{r}\right) \text { for each } j \in \mathcal{I} \text { and } j=c \\
E^{i} & \geq L_{c}+L_{1}^{i}+\ldots+L_{n}^{i}
\end{aligned}
$$

where $L_{m j}=\sum_{k \in \mathcal{I}_{m}} L_{j}^{k}$ and $L_{f j}=\sum_{k \in \mathcal{I}_{f}} L_{j}^{k}$. Given the pooling of resources from the collective plot and the private plots in $\mathcal{I}_{z}$, optimisation requires household members to allocate labour across these plots to equate the corresponding marginal products of labour. Therefore, the allocation of labour across these plots will be efficient. As for the remaining private plots, consider household members $i, j \notin \mathcal{I}_{z}, i$ male and $j$ female, who both contribute labour to the collective plot and each other's private plots. We obtain the following equations from the first-order conditions to (5) (the steps are shown in the Theoretical Appendix):

$$
\begin{aligned}
& \hat{\delta}_{i c} \frac{\left(y_{z}\right)^{\rho}}{L_{m c}}=\frac{v\left(\mathbf{x}_{i}\right)}{L_{m i}}=\delta_{i j} \frac{v\left(\mathbf{x}_{j}\right)}{L_{m j}} \\
& \hat{\delta}_{j c} \frac{\left(y_{z}\right)^{\rho}}{L_{f c}}=\delta_{j i} \frac{v\left(\mathbf{x}_{i}\right)}{L_{f i}}=\frac{v\left(\mathbf{x}_{j}\right)}{L_{f j}}
\end{aligned}
$$

$$
\begin{aligned}
& { }^{5} \text { Specifically, } \Lambda=\sum_{i=1}^{n} \sum_{p=1}^{\bar{p}} \zeta_{i p c}+(n-1) \text { and } \zeta_{j p c}=\left(\frac{\delta_{j c}}{\delta_{p v}}\right)^{\frac{1}{\rho-1}} . \\
& { }^{6} \Lambda_{v}=1+\sum_{p=1}^{\bar{p}} \zeta_{p v}, \zeta_{p v}=\left(\frac{\delta_{1 v}}{\delta_{p v}}\right)^{\frac{1}{\rho-1}} .
\end{aligned}
$$


where $\hat{\delta}_{i c}=\left(\frac{y_{c}}{\bar{y}_{z}}\right)\left[\delta_{i c}+\sum_{k \in \mathcal{I}_{z}} \sum_{p=1}^{\bar{p}} \delta_{i k} \delta_{p v}\left(\zeta_{k p c}\right)^{\rho}\right]$. The term $\hat{\delta}_{i c}$ captures $i$ 's incentive to provide labour on the collective plot, taking into account one's own preference for the household public good, as represented by $\delta_{i c}$, and the fact that income from private plots in $\mathcal{I}_{z}$ are pooled together with that from the collective plot.7 Then we obtain a relationship between the labour use intensity on the collective plot and each private plot (the derivation is shown in the Theoretical Appendix):

$$
\begin{aligned}
\ln \left(\frac{L_{m c}}{A_{c}}\right)-\ln \left(\frac{L_{m i}}{A_{i}}\right)= & \frac{\rho}{[1-\rho(1-\alpha)]} \ln \left[\frac{R_{c}\left(q_{c}, \mathbf{r}\right)}{R_{i}\left(q_{i}, \mathbf{r}\right)}\right]+\left[\frac{\rho-1}{1-\rho(1-\alpha)}\right] \ln \left(\frac{A_{c}}{A_{i}}\right) \\
& \left.+\left[\frac{1-\rho \beta_{2}}{1-\rho(1-\alpha)}\right] \ln \left(\hat{\delta}_{i c}\right)+\left[\frac{\rho \beta_{2}}{1-\rho\left(\beta_{1}+\beta_{2}\right)}\right]\left[\ln \left(\hat{\delta}_{j c}\right)-\ln \left(\delta_{j i}\right)\right] 8\right) \\
\ln \left(\frac{L_{m c}}{A_{c}}\right)-\ln \left(\frac{L_{m j}}{A_{j}}\right)= & \frac{\rho}{[1-\rho(1-\alpha)]} \ln \left[\frac{R_{c}\left(q_{c}, \mathbf{r}\right)}{R_{j}\left(q_{j}, \mathbf{r}\right)}\right]+\left[\frac{\rho-1}{1-\rho(1-\alpha)}\right] \ln \left(\frac{A_{c}}{A_{j}}\right) \\
& +\left[\frac{\rho \beta_{2}}{1-\rho(1-\alpha)}\right] \ln \left(\hat{\delta}_{j c}\right)+\left[\frac{1-\rho \beta_{2}}{1-\rho(1-\alpha)}\right]\left[\ln \left(\hat{\delta}_{i c}\right)-\ln \left(\delta_{i j}\right)\right](9)
\end{aligned}
$$

According to equations (8) and (9), any differences in the use of male labour (per unit area) is due to differences in plot characteristics and the differential effects of rainfall, relative preferences for household public goods versus private goods, and (lack of) altruism between household members (as represented by $\delta_{i j}$ and $\delta_{j i}$ ). If $\delta_{i j}=\delta_{j i}=1$ and $\delta_{i c}=\delta_{j c}$, then preferences across household members are identical and we obtain an efficient allocation of labour across farm plots. We can represent lower levels of altruism by using smaller values of $\delta_{i j}$ or $\delta_{j i}$ and this would lead to a widening gap in the intensity of labour use between the private plots and the collective plot, in favour of the collective plot. Equivalent results for female labour use intensities are shown in the Theoretical Appendix.

Having derived household expenditures as a function of income, and labour allocation as a function of intra-household land allocation and rainfall, we can obtain intra-household land allocation that is optimal from the head's point of view and provides every other household member their reservation utility. We do not discuss the land distribution in further detail here as its relation to intra-household altruism is theoretically ambiguous 8 Note that equations (8) and (9) relate to total labour on farm plots; they do not pin down individual labour contributions. However, the same equations can serve to analyse individual labour contributions if we impose some additional structure on the model. We show how this can be done in the Theoretical Appendix.

Plot Yields: Using equations (8) and (9), we can also compute the gap in yields between the

\footnotetext{
${ }^{7}$ Note that if $\mathcal{I}_{z}=\emptyset$ (i.e. no household member contributes to the household public good), then $\bar{y}_{z}=y_{c}$ and $\hat{\delta}_{i c}=$ $\delta_{i c}$. In this case, $i$ 's only incentive to contribute on the collective plot is based on his or her own preference for the household public good.

${ }^{8}$ Please see Kazianga and Wahhaj (2016) for further details.
} 
collective plots and the private plots (the derivation is shown in the Theoretical Appendix):

$$
\begin{aligned}
\ln \left(\frac{y_{c}}{A_{c}}\right)-\ln \left(\frac{y_{i}}{A_{i}}\right) & =\Gamma^{\prime} \ln \left[\frac{R_{c}\left(q_{c}, \mathbf{r}\right)}{R_{i}\left(q_{i}, \mathbf{r}\right)}\right]+\Gamma \ln \left(\frac{A_{c}}{A_{i}}\right)+\left[\frac{\beta_{1}}{1-\rho(1-\alpha)}\right] \ln \left(\hat{\delta}_{i c}\right) \\
& +\left[\frac{\beta_{2}}{1-\rho(1-\alpha)}\right]\left[\ln \left(\hat{\delta}_{j c}\right)-\ln \left(\delta_{j i}\right)\right] \\
\ln \left(\frac{y_{c}}{A_{c}}\right)-\ln \left(\frac{y_{j}}{A_{j}}\right) & =\Gamma^{\prime} \ln \left[\frac{R_{c}\left(q_{c}, \mathbf{r}\right)}{R_{j}\left(q_{j}, \mathbf{r}\right)}\right]+\Gamma \ln \left(\frac{A_{c}}{A_{j}}\right)+\left[\frac{\beta_{2}}{1-\rho(1-\alpha)}\right] \ln \left(\hat{\delta}_{j c}\right) \\
& +\left[\frac{\beta_{1}}{1-\rho(1-\alpha)}\right]\left[\ln \left(\hat{\delta}_{i c}\right)-\ln \left(\delta_{i j}\right)\right]
\end{aligned}
$$

where $\Gamma=\left(\beta_{1}+\beta_{2}\right)\left[\frac{\rho-1}{1-\rho(1-\alpha)}\right]$ and $\Gamma^{\prime}=\frac{1+\rho \alpha}{1-\rho(1-\alpha)}$. From 10 and 11 , we find that any differences in yields between the collective plots and the private plots are, once again, due to differences in plot characteristics, relative preferences between household public goods and private goods, and altruism between household members. If $\delta_{i j}=\delta_{j i}=1$ then, allowing for differences due to plot characteristics, and preferences for household public goods, the yields across collective plots and private plots are identical as implied by efficiency in agricultural production. For lower values of $\delta_{i j}$ and $\delta_{j i}$, a yield gap opens up in favour of the collective plot.

Most importantly, equations (10) and (11) - and the corresponding equations for labour use intensities - provide a link between the allocation of productive resources within the household and the extent of altruism between household members, which can be investigated with plot-level data from agricultural households. We discuss and implement empirical tests implied by these equations in Section (5).

Intra-household Transfers and Consumption Risk-sharing: As per the production function in (1), the effects of rainfall on farm output can depend on plot quality. This means that household members with private plots of varying quality are potentially subject to idiosyncratic shocks. Therefore, they can benefit from an intra-household risk-sharing agreement. Such an agreement can take the form of a set of state-contingent transfers $\left\{\tau_{1}(\mathbf{y}), . ., \tau_{n}(\mathbf{y})\right\}$ from each household member to a common fund satisfying the condition $\sum_{i=1}^{n} \tau_{i}(\mathbf{y})=0$ for each $\mathbf{y}$. We can show that, given such an agreement, equation (4) continues to hold for individuals who contribute to the household public good, while $x_{j p}=\zeta_{p v}\left(\Lambda_{v}\right)^{-1}\left[y_{j}-\tau_{j}(\mathbf{y})\right]$ for those who don't. It follows that if the transfers induce every household member to make a positive contribution to $z$, then we obtain complete income pooling within the household, with a fixed proportion of total income spent on each good:

$$
z=\left(\Lambda^{-1}\right) y_{t o t}, x_{j p}=\zeta_{j p c}\left(\Lambda^{-1}\right) y_{t o t} \text { for } j \in \mathcal{I}, p=1,2, . ., \bar{p}
$$

where $y_{t o t}=y_{c}+\sum_{j=1}^{n} y_{j}$. It is straightforward to show that these consumption levels correspond to those required for efficient risk-sharing between household members for some set of Pareto weights.

However, there may be no enforcement mechanism to implement a transfer agreement, which means that risk-sharing has to rely on voluntary transfers between household members. For any given $\mathbf{y}$, the maximum transfer that $i$ is willing to make in a self-enforcing agreement is increasing 
in $\delta_{i j}$, because a larger value of $\delta_{i j}$ translates into a stronger preference for the expenditures made by $j 9^{9}$ Consequently, if $\delta_{i j}, \delta_{j i}$ are sufficiently large, the transfer agreement required for efficient risk-sharing will be self-enforcing. For low values of $\delta_{i j}, \delta_{j i}$, some degree of risk-sharing can be achieved through smaller vountary transfers.

\section{Description of Survey and Descriptive Statistics}

The dataset we use for the empirical exercise in this paper is composed of a panel of households surveyed by the Office of Agricultural Statistics of the Ministry of Agriculture in Burkina Faso. The sample consists of 747 villages with about 6 households per village and is designed to be nationally representative. The survey rounds that we used were fielded in 2010, 2011 and 2012. The survey was mainly focused on collecting information related to farming. Hence, it contains detailed information on household demographics and farm activities, but limited information on consumption. The enumerators lived in the sampled villages and were instructed to visit the sample households at the end of each farming activity, i.e. field preparation, planting, weeding and harvesting. Information relating to each farm plot was obtained from the individual in the household who had responsibility for it during that season. The collected information includes farm plot characteristics (farm size, topography, location in relation to the homestead), production technologies, agricultural inputs and outputs, and farm labour. Importantly for our analysis, the survey distinguished between household plots managed collectively and plots managed individually.

Each plot owner reported, for each worker who had worked on the plot, the number of personlabour days that he or she contributed 10 The survey includes information about the identity of the worker, which allows us to distinguish between workers who were household members (including the plot owner), and those who did not belong to the household. Most of the farm labour - about $97 \%$ per hectare - was provided by household members. Therefore, we disregard outside labour and focus on the labour provided by household members for the analysis.

The survey did not field a consumption module, but food consumption could be inferred from the survey modules on crop harvest, livestock and non-farm income. The respondent for each plot reported the quantity harvested that was consumed, stored or sold and, in case of sales, whether and how much of the proceeds were used for food purchases. The livestock module provides information on own consumption of livestock and the amount of revenues from sale of livestock used for food purchases. Similarly, the module on non-farm activities reports the amount of income used for food purchases. We use the combined information from these modules to construct three categories of food consumption: (i) cereals (millet, white and red sorghum, corn, fonio and rice), (ii) pulses and vegetables, (iii) other food categories. In the case of the consumption of home produce, the

\footnotetext{
${ }^{9}$ Ligon, Thomas and Worrall (2002) and Fafchamps (1992) investigate in detail how changes in preference parameters affect the scope of risk-sharing within a group in the absence of external enforcement.

${ }^{10}$ We have no information on the number of hours of work that constitutes a day of labour but, as these figures were reported by plot owners rather than workers, it is unlikely that a token amount of labour would be reported as a "day" of work.
} 
quantities were converted into monetary values using the village average sale price per unit.

The survey collected information from three income sources: crop income, livestock sales, and non-farm income. We measure crop income as the total value of harvest. We convert total harvest into monetary values using the village average sale prices mentioned above. The survey recorded sales of livestock and non-farm income in monetary values. We add together income from these three sources to obtain total household income.

Characteristics of Nuclear and Extended Family Households: We use the demographic information in each survey to distinguish between extended and nuclear family households. Using the definitions given in the preceding section, we have 8,080 observations of extended family households and 5,723 observations of nuclear family households from the Ministry of Agriculture survey, as shown in Table 211 On average, extended family households are larger, consisting of 11.78 household members versus 7.30 for nuclear family households ${ }^{12}$ But this difference is almost exactly accounted for by the average number of extended family members in the former households (4.59). Furthermore, extended family households have significantly more married men (1.76 versus 1.04 ) and the household head have significantly more wives (1.57 versus 1.47$)$. The head in extended family households is also slightly older and marginally more likely to be literate. Turning to the farm characteristics in the table, we see that extended family households have significantly more land, and have, on average, more farm plots under cultivation in a specific year.

Table 4 provides descriptive statistics by farm plot, broken down by plot-type (i.e. private plots and collective plots) and by household-type (nuclear family households and extended family households). Collective plots managed by the household head are an order of magnitude larger than the other plots (average area of 4.21 hectares as compared to 0.50 hectares for male private plots) but labour use intensity and yields are broadly similar across all types of plots. Collective plots in extended family households are significantly larger than in nuclear family households, but nuclear family households allocate a slightly larger share of household farm land to the collective plots. The yield gap between the most productive and the least productive type of plots is larger within extended family households 13 This suggests that extended family households may be relatively less efficient than nuclear family households in allocating its productive resources. We will revisit these issues in the econometric analyses.

Shadow Price of Family Land and Labour: The data on labour and land allocation within the household allows us to calculate how much labour an adult household member contributes to the household's collective plots per unit of land it receives for private farming. In the absence of labour

\footnotetext{
${ }^{11}$ The survey manual defines a household as a "group of individuals usually linked by ties of blood or marriage, usually living together and producing together, where budgetary authority, at least in theory, lies with a single person within the group called the 'household head"' (Burkinabe Ministry of Agriculture, Manuel de l'enqueteur, Enquete Permanente Agricole, 2009; authors' translation).

${ }^{12}$ For the purpose of the survey, household members included those who had been living with the household at least six months or had the intension of doing so, and excluded those who had been absent six months or more.

${ }^{13}$ For nuclear households, the ratio of the least productive plots (female plots) to the most productive plots (male plots) is 0.89 . In extended households the ratio of the least productive plots (female plots) to the most productive plots (head managed common plots) is 0.86 .
} 
contribution by household members, the head would have to hire workers to work on the collective plot; and in the absence of the land that these household members receive from the household head for private farming, they would, at least in theory, have to make use of land markets. Therefore, the ratio described above can be regarded as the "shadow price of land" within the household or the inverse of the "shadow price of labour" 14 Table 4 summarizes the "shadow" prices of land and labour implied by the allocation of land and labour discussed above. On average, nuclear family household members contribute 263 days of labour on collective plots per hectare of land (allocated for private farming) while extended household members contribute 209 days of labour on collective plots for one hectare of land. Looking at the shadow price by gender, we find that men and women in extended family households contribute, respectively, 446 and 181 days of labour per hectare of land while the corresponding figures for nuclear family households are 320 and 159. Overall, the patterns are consistent with the hypothesis that household heads are able to extract more labour from nuclear family members. Another interpretation of these patterns is that the household head's commitment to allocate the proceeds from the collective plots to household public goods is more credible (e.g. because of stronger altruism) in nuclear family households than for extended family households, and this induces household members to voluntarily contribute more labour on collective plots.

\section{Household Agricultural Production}

Informational asymmetry and commitment problems can prevent household members from engaging in the exchange of productive resources - e.g. land, labour and other agricultural inputs - and therefore prevent efficiency in household production (Udry 1996). In this context, altruism within the household can induce voluntary intra-household transfers and enable the household to achieve a more efficient allocation of resources in the spirit of the well-known 'Rotten Kid Theorem' (Becker 1993). One of the key distinguishing features between extended family households and nuclear family households, besides household size and the demographic composition, is, potentially, the level of altruism between household members. Therefore, we investigate whether these two types of households differ in terms of their efficiency in agricultural production.

We implement a test of efficiency in household production using the approach first adopted by Udry (1996). Specifically, we estimate a farm plot yield equation which includes household characteristics, physical characteristics of the plot and features of plot ownership, as follows:

$$
Q_{h t c i}=\mathbf{X}_{h c i} \boldsymbol{\beta}+\mathbf{G}_{h i} \boldsymbol{\gamma}+\lambda_{h t c}+\varepsilon_{h t c i}
$$

where $Q_{h t c i}$ is the $\log$ of yield on plot $i$ in year $t$, planted to crop $c$ and belonging to household $h ; \mathbf{X}_{h c i}$ is a vector of physical characteristics of plot $i$ including the plot area, topography and

\footnotetext{
${ }^{14}$ The previous literature has highlighted the practice of labour and land 'exchanges' within the family - albeit in the context of bequests - in the case of India and Israel (Rosenzweig 1985; Rosenzweig 1988; Kimhi 2004). A number of studies on West Africa have also emphasized that the contribution of labour to collective farm plots constitutes part of an intrahousehold exchange (see, for example, Von Braun and Webb 1989).
} 
location in relation to the household; $\lambda_{h t c}$ is a household-crop-year fixed effect; and $\mathbf{G}_{h i}$ is a vector of characteristics of plot $i$ in household $h$ including, for example, the gender of the person responsible for the plot and whether the plot is classified as being 'collective' or 'private'.

Equation (13) can also be seen as an empirical equivalent of equations (10) and (11), which provide a specific interpretation to yield differentials between collective plots and private plots. They imply that, after controlling for plot characteristics and household-crop-year fixed-effects, the remaining differentials can be attributed to relative preferences for household public goods, and the level of altruism towards the private plot owner by other household members.

Table 3 shows the estimated results for equation (13), using agricultural data from the survey. In these regressions, we divide the farm plots into three categories: (i) household collective plots, (ii) private plots managed by male household members, and (iii) private plots managed by female household members. We find that the yields achieved on private plots managed by men and women are lower than that achieved on household collective plots (the omitted category) and the differences are statistically significant at the $1 \%$ level in each instance. This holds true for the full sample of households (regression results shown in column 1 of the table) as well as for the subsample of extended family households (column 2) and nuclear family households (column 3).

Pareto efficiency would imply that yields across all three plot categories are equal, after controlling for the crops planted, the physical characteristics of the plot and the skills of the plot owner. An F-test for the hypothesis that the yields are the same across all three plot categories is strongly rejected for both extended family households and nuclear family households (yielding an F-statistic of 244.8 in the first case, and 53.25 in the second case). The rejection of efficiency in household production is consistent with findings in the existing literature (Udry 1996; Goldstein and Udry, 2008; Kazianga and Wahhaj, 2013; Guirkinger et al., 2015; Akresh et al., 2016).

In words, these households are achieving significantly higher yields on collective plots compared to private plots which have been planted with the same crops, controlling for observable physical characteristics of the plot and the plot owner. But the divergence in plot yields between collective plots and private plots is higher for extended family households than for nuclear family households. The estimated coefficients imply that, relative to household collective plots, private male plots achieve yields which are $24 \%$ lower in extended family households and $13 \%$ lower in nuclear family households; the corresponding figures for female plot yields are $42 \%$ and $29 \%$ respectively.

The gender difference in plot yields has been noted in the previous literature, with potential explanations provided by Goldstein and Udry (2008) and Kazianga and Wahhaj (2013). However, the gap between extended family and nuclear family households is just as striking. If we assume that members of the nuclear family exhibit higher levels of altruism towards one another than towards extended family members and unrelated individuals, these patterns are consistent with the theoretical predictions. 


\subsection{Plot Yield Dispersions}

We can also use the data on plot yields to see graphically the variation in plot yields across different plots within nuclear family households and within extended family households. In Figure 1, we plot the residuals from estimations of equation 13 without $\mathbf{G}_{h i}$ - i.e. without the male and femaleplot dummies, and the age and education of the plot manager. The resulting graphs show the distribution of plot yields for farm plots belonging to the same household and planted to the same crop, in the same year, after controlling for physical characteristics of the plots.

For comparison, we also show the residuals from corresponding regressions for the pooled sample with (i) village-crop-year fixed effects, and (ii) individual-crop-year fixed effects. Greater dispersion in the residuals indicates greater inefficiency in the allocation of farm resources within the relevant group (and more scope for improving output through a reallocation of resources). The household-level distributions, for both subsamples, lie between the village-level and individual-level distributions. This is consistent with the findings by Udry (1996) and Kazianga and Wahhaj (2013) and implies that the household is more efficient than the village at allocating resources across farm plots that belong to the group, but not as efficient as the individual.

We also see from the figure that there is greater variation in plot yields across apparently identical plots for extended family households as compared to nuclear family households. The equality of the two distributions is rejected at any conventional level using a Kolmogorov-Smirnov test. The graphs for the nuclear and extended family households are consistent with our estimated coefficients in the previous section and suggests that nuclear family households are more efficient at allocating productive resources across farm plots than extended family households.

\subsection{Explaining the Plot Yield Gaps across Different Household Types}

Why are plot yield dispersions greater in the case of extended family households as compared to nuclear family households? Table 2 shows that, on average, extended family households have 11.78 members while nuclear family members have 7.30 members, with the difference being strongly statistically significant. The presence of extended family members in the former group largely accounts for this difference: on average, extended family household have 4.59 extended family members while nuclear family households, by definition, have none. The table also shows that, while there is little difference in the head's marital status between the two groups, the head in extended-family households, on average, have more spouses; i.e. they are more likely to be in polygamous relationships. They are also, on average, slightly older. Therefore, the difference in household sizes, the extent of polygyny and the presence of extended family members present themselves as natural candidates to account for the observed difference in plot yield dispersions. In this section, we investigate the hypothesis relating to the presence of extended-family members while the alternative hypotheses are investigated in section 7 .

We introduce a set of categorical variables to the plot yield regressions indicating the relation 
of the plot owner to the household head. The estimated results for the whole sample, the sample of extended family households and nuclear family households are shown in Table 4. The omitted plot category in the table is 'collective plots managed by the household head'. We introduce a single category for all other collective plots, and separate categories for private plots farmed by different relations of the household head. The first point to note for this table is that, even putting aside the collective plots, the household head achieves a higher yield on private plots compared to other household members, with the differences being statistically significant.

Being outside of the nuclear family does not, however, seem to be a disadvantage in itself: we cannot reject the hypotheses that (i) the yield coefficient for the household head's sons is the same as that for other male relatives and unrelated male household members; and that (ii) the yield coefficient for the household head's daughters is the same as that for other female relatives and unrelated female household members. This holds true for both the subsample of extended family households and for the full sample.

The wider dispersion in plot yields in extended family households can be traced to two sources. First, in nuclear family households, the household head achieves almost the same yield on his private plots as on the collective plots under his control (the coefficient is not statistically significant) while in extended family households, the corresponding yield gap is about $19 \%$ (and statistically significant). Second, the yield gap between the head's collective plots and the private plots farmed by members of the nuclear family (i.e. the son, daughter and spouse of the household head and the head himself) is smaller in the case of nuclear family households than for extended family households. A joint test of equality between the relevant coefficients for the two subsamples is strongly rejected.

In summary, the wider dispersion of plot yields in extended family households is not due to the presence of extended family members per se. Rather, it is because the plot yield gap (relative to the household's collective plots) is larger for household members in extended family households than for household members in nuclear family households who hold the same 'position' (defined in terms of their relation to the household head). To better understand the source of these plot yield differences, we examine how agricultural inputs, in particular farm labour, is allocated across household plots. We discuss this in the following section.

\subsection{Allocation of Labour Across Farm Plots}

If the production technology used by agricultural households exhibits diminishing marginal product of labour, then productivity efficiency requires that farm plots with the same physical characteristics (including plot size, topography, location, etc.) and planted to the same crops, should make use of equal amounts of labour. If not, it would be possible to increase output by reallocating labour towards farm plots with lower labour use intensity. Therefore, we can test for efficiency in labour allocation across farm plots belonging to the same household by using a specification similar to (13). 
We estimate the following equation separately for nuclear family and extended family households and different labour types:

$$
l_{h t c i}^{j}=\mathbf{X}_{h c i} \boldsymbol{\beta}^{j}+\mathbf{G}_{h i} \boldsymbol{\gamma}^{j}+\lambda_{h t c}+\varepsilon_{h t c i}^{j}
$$

where $l_{h t c i}^{j}$ is the log of the amount of labour of type $j$ applied to plot $i$ per unit area, in year $t$, and plot $i$ belongs to household $h$ and is planted to crop $c$. The labour types include 'adult male', 'adult female', 'child' and 'total'. Equation (14) can be regarded as an empirical equivalent of equations (8) and (9), which imply that the difference in labour use intensity between collective plots and private plots depend on preferences for household public goods and altruism within the household towards the private plot owner.

The results are shown in Table 5. First, we observe that the labour use intensity (for total labour) is significantly higher for the collective plots managed by the household head than for all other types of plots owned by the household (controlling for plot characteristics and the planted crop); and this holds for both nuclear family and extended family households. Therefore, these households are not allocating labour efficiently across farm plots.

Second, the labour use intensity gap between the head's collective plots and the private plots farmed by members of the nuclear family (i.e. the son, daughter and spouse of the household head and the head himself) is smaller in the case of nuclear family households than for extended family households. A joint test of equality between the relevant coefficients for the two subsamples is strongly rejected. This is exactly the pattern we obtained in the case of plot yields and is consistent with the theoretical predictions above.

Turning to extended family households, we cannot reject the hypothesis that the labour use intensity coefficient (for total labour) of the household head's sons is the same as that for other male relatives and unrelated male household members. The corresponding coefficients for the household head's daughter, other female relatives and unrelated female household members are very close $(-0.65,-0.68$ and -0.72$)$ but estimated precisely enough that we can reject the hypothesis that they are equal. Nevertheless, the pattern is broadly similar to what we saw in the case of plot yields: private plots managed by household members who are not part of the head's nuclear family are not at a disadvantage relative to those of the head's own children (of the same gender) in terms of labour inputs.

In summary, the findings discussed in this section suggests that the wider dispersion of plot yields within extended family households can be accounted for by the wider dispersion of labour use intensity within these same households.

\section{Individual Labour Contributions on Privately-Owned Plots}

Estimates based on equation (14) reveal the pattern of labour use intensities across farm plots but they do not tell us how different household members are dividing their own labour across different plots maintained by the household. To investigate the latter, we estimate the following 
equation using data on labour contributions by individual household members on each farm plot:

$$
l_{j h t c i}=\mathbf{X}_{h t c i} \boldsymbol{\beta}_{j}+\mathbf{W}_{j h t} \boldsymbol{\zeta}_{j}+\lambda_{j h t c}+\varepsilon_{j h t c i}
$$

where $l_{j h t c i}$ is the log of total labour per unit area provided by individual $j$ in household $h$ on private plot $i$ planted to crop $c$ in period $t$. The vector $\mathbf{X}_{h t c i}$ includes the characteristics of plot $i$ (as before) and $\mathbf{W}_{j h t}$ includes the worker's characteristics including gender, age and education; and the error term $\varepsilon_{j h t c i}$ is clustered at the village level in the estimation. Equation (15) can be regarded as the empirical equivalent of equations (36) and (37) provided in the Theoretical Appendix ${ }^{15}$

The estimated results are shown in Table 9. For extended-family households we estimate equation (15) separately for workers who belong to the head's nuclear family (column 2) and those who don't (column 1). In each case, we include explanatory variables to indicate the relation of the plot owner to the head. This allows us to compare labour provided within owner-worker pairs that have a nuclear family tie to pairs that do not. In column 3, we provide equivalent estimates for nuclear family households.

The estimated coefficients for plot ownership in column (2) indicate that nuclear family members allocate more labour on plots owned by the head, head's spouse, daughter and son than on plots owned by the head's non-nuclear relations. By contrast, the estimated coefficients in column (1) indicate that extended family members allocate less labour on plots owned by members of the head's nuclear family than on plots owned by the head's non-nuclear relations. These differences are all statistically significant at conventional levels.

Furthermore, comparing the estimated coefficients in columns (1) and (2), we find that - taking the individual's labour on his/her own private plot as a reference point - the nuclear family members allocate more labour on private plots owned by the head, head's spouse, daughter and son than do extended family members. On the other hand, extended family members allocate significantly more labour on plots owned by the head's non-nuclear relations than do members of the nuclear family. Except in the case of the head's private plots, the null hypotheses that any of the plot ownership coefficients in columns (1) and (2) are equal is strongly rejected.

Turning to column (3), we find that the estimated plot ownership coefficients are close to zero and statistically insignificant. In other words, there are no statistically significant differences in the allocation of labour across private plots within nuclear family households once plot characteristics, worker characteristics and household-crop-year fixed effects are controlled for.

These patterns are consistent with the theoretical predictions and provide strong evidence that the allocation of labour across private plots are a function of family ties, and that levels of altruism are higher for nuclear family ties than for non-nuclear relations within the same set of households.

\section{Individual Labour Contributions on the Household's Collective Plots}

\footnotetext{
${ }^{15}$ Note that we do not control for the number of female and male workers on each plot, as implied by the theoretical equations as these are potentially endogenous. To the extent that the number of workers can be proxied by household demographic composition and familial ties, their effects will be subsumed in the household fixed-effects.
} 
In Table 10, we provide parallel estimates for the total labour contribution of each household member to the household's collective plots. Explanatory variables include the total size of the individual's private plots and of the household's collective plots, demographic characteristics of the household, and worker characteristics. In columns 1-3, we control for household fixed effects and observable household characteristics such as the area of the collective plot and the demographic composition of the household. In columns 4-6, we control for household-year fixed effects, which allows us to account for time-varying household and village-level unobservables. In particular, we account for annual variations in prices (crops, land and wages) that can influence labour supply and land allocation. It is reassuring that the point estimates and the statistical significance are stable across the two specifications.

The omitted relationship category is the 'household head'. Focusing on columns 1-3, we see that the estimated coefficient in all the other relationship categories is negative and statistically significant. For a given relationship with the household head (e.g. a spouse, son or daughter) the coefficient is more negative in the case of extended family households than for nuclear family households. For example, the estimates imply that, within extended family households, the head's son contribute $37 \%$ less labour on the collective plots than the head himself (statistically significant at the $1 \%$ level) while, in nuclear family households, there is no statistically significant difference between their labour contributions. A test of the equality of the coefficients for nuclear family members in columns 2 and 3 is strongly rejected.

The point estimates also indicate that the son contributes more labour than other male relations and unrelated male individuals living within the same household, but the differences are small and we cannot reject the hypothesis that they are equal. We are able to reject the hypothesis that the daughter, other female relations and unrelated female individuals all contribute the same amount of labour to the collective plots. We obtain similar patterns when we control for household-year fixed effects in columns 4-6.

In summary, the estimates reveal sharp differences, between nuclear and extended family households, in the head's spouse, son and daughter's labour on the collective plots (taking the head's own labour as a reference point). On the other hand, the differences in labour contributions between nuclear and extended family members within the same household is less marked. This pattern suggests that individuals within nuclear family households - irrespective of their relation to the household head - have preferences for household public goods more closely aligned with that of the head than individuals within extended family households.

\section{Intra-Household Risk-Sharing}

As discussed in Section 3.1, in the absence of formal contracts, households where individuals have 'stronger ties' or higher levels of altruism among them should be more effective at sharing risk among its members. It follows that if one exhibits a higher level of altruism towards a nuclear 
family member, as compared to a cohabiting extended-family member or unrelated individual, then nuclear family households should serve as more effective risk-sharing units than extended family households. In this section, we use data on farm income, rainfall shocks, consumption expenditures and child anthropometric data to test this hypothesis in two different ways. Rainfall data is drawn from the Climate Research Unit (CRU) at the University of East Anglia, which provides monthly precipitation data on a $0.5 \times 0.5$ degree grid. We have geographic coordinates of each of the sample villages. Hence, we are able to link each village to a CRU grid and the rainfall covering the period from 1940 to 2012 .

\subsection{Efficiency in Consumption Expenditures}

Rainfall shocks can have a differential impact on the output and income generated from different farm plots owned by the same household, due to differences in skill of the plot managers, plot characteristics, crops planted and inputs applied. Therefore, variations in rainfall can be used to examine whether different income shocks - affecting the income from distinct plots - affects household consumption differently. These comparisons can also provide the basis for testing for efficient risk-sharing in consumption decisions within the household. Before proceeding to discuss the empirical results, we briefly describe the methodology used to analyse consumption decisions. The methodology is adapted from Duflo and Udry (2004), where a more general version of the theory is developed and the intuition discussed in greater detail.

Following a common approach in the literature (e.g. Fafchamps, Udry and Czukas 1998, Kazianga and Wahhaj 2013, Paxson 1992), we assume the following log-linear relationship between rainfall and household farm income:

$$
\log \left(y_{h t}\right)=\sum_{s=m, f, c}\left(\mathbf{X}_{s h t} \otimes \mathbf{R}_{v t}^{\prime}\right) \boldsymbol{\gamma}_{s}+\lambda_{h}+\lambda_{v t}+\xi_{h t}
$$

where $y_{h t}$ represents total farm income for household $h$ in period $t, \mathbf{X}_{s h t}$ is a vector of physical characteristics of plots of type $s$ (private male, private female, or collective), $\mathbf{R}_{v t}$ is a vector of rainfall measures in village $v$ in period $t, \lambda_{h}$ and $\lambda_{v t}$ are, respectively household and village-year fixed effects and $\xi_{h t}$ is an error term to capture other exogenous shocks that affect household farm income in period $t \sqrt{16}$ The estimated coefficients from $\sqrt{16}$ are used to compute a linear combination of rainfall variables as follows: $\hat{y}_{s h t}=\left(\mathbf{X}_{s h t} \otimes \mathbf{R}_{v t}^{\prime}\right) \hat{\gamma}_{s}$. These fitted values represent the part of (the $\log$ of) total farm income that is explained by the effect of rainfall variations on different categories of farm plots owned by the household .

Ideally, we would use individual consumption data to test for consumption efficiency within the household. But due to data limitations imposed by the agricultural household survey, we base our efficiency tests on household consumption of different categories of food. Let us denote by $f \subset\{1,2, . ., \bar{p}\}$ the subset of consumption goods which relate to food consumption.

\footnotetext{
${ }^{16}$ Note that measures of rainfall do not appear in the equation on their own as these effects are entirely subsumed in the village-year fixed-effects.
} 
Then, if there is efficiency in household consumption expenditures, using (12) we can write total household expenditures on food as $x_{f}=\sum_{p \in f} \sum_{j \in \mathcal{I}} \zeta_{j p c}\left(\Lambda^{-1}\right) y_{t o t}$, and expenditures on a particular food category $p \in f$ can be written as $x_{p}=\kappa_{p} x_{f}$ where $\kappa_{p}$ is a constant.17 This last equation implies a version of the test of consumption efficiency developed by Duflo and Udry (2004): that different rainfall shocks affect consumption in food category $p$ only via their effects on total food consumption.

Note that the fitted values $\hat{y}_{j h t}$ described above are, in effect, linear combinations of different measures of rainfall. They are suitable measures of household-specific rainfall shocks as they capture the effects of rainfall on income from different categories of farm plots. Therefore, we can use them to test the consumption efficiency hypothesis as follows. First, we estimate the effects of the rainfall measures on each food category and total food expenditures as follows:

$$
\begin{aligned}
\log \left(x_{f h t}\right) & =\sum_{s=c, m, f} \pi_{f s} \hat{y}_{s h t}+\mathbf{H}_{h v t} \boldsymbol{\zeta}_{f}+\lambda_{f h}+\lambda_{f v t}+\nu_{f h t} \\
\log \left(x_{p h t}\right) & =\sum_{s=c, m, f} \pi_{p s} \hat{y}_{s h t}+\mathbf{H}_{h v t} \boldsymbol{\zeta}_{p}+\lambda_{p h}+\lambda_{p v t}+\nu_{p h t}
\end{aligned}
$$

where $x_{f h t}$ represents total food expenditures, and $x_{p h t}$ represents expenditures in food category $p$, in household $h$ in period $t$. The vector $\mathbf{H}_{h v t}$ includes, potentially time-varying, household characteristics including the demographic composition of the household. The terms $\lambda_{f h}$ and $\lambda_{p h}$ are household fixed-effects and $\lambda_{f v t}$ and $\lambda_{p v t}$ denote village-year fixed-effects. This specification controls for village-level annual covariate shocks, and hence is frequently used in the village-level risk sharing literature (e.g. Townsend 1994, Ravallion and Chaudhuri 1997, and Kazianga and Udry 2006). Consumption efficiency requires that

$$
\frac{\pi_{p s}}{\pi_{f s}}=\frac{\pi_{p s^{\prime}}}{\pi_{f s^{\prime}}} \text { where } s, s^{\prime} \in\{c, m, f\}
$$

Following Duflo and Udry (2004), we test for (19) using a non-linear Wald test, separately for nuclear and extended family households.

\subsubsection{Results}

As explained in Section 4, we use information from the survey modules on plot harvest, livestock and non-farming activities to construct measures of food consumption, broken down into three categories: (i) cereals, (ii) pulses and vegetables, and (iii) other food items. The methodology outlined above can be used to test for consumption efficiency within the household using these food categories.

Table 11 shows the estimates of equation (16) using, as explanatory variations, the deviation of rainfall from its long-run average interacted with the household's farm area in different land and

$$
{ }^{17} \kappa_{p}=\frac{\left(\sum_{j \in \mathcal{I}} \zeta_{j p c}\right)}{\left(\sum_{p^{\prime} \in f j \in \mathcal{I}} \sum_{j p^{\prime} c}\right)}
$$


ownership categories. In column (1), we use all ownership categories while in the other columns we include only land allocated to (2) collective, (3) male private and (4) female private plots to construct measures of alternative types of rainfall shocks. We also report on F-tests for the joint significance of the estimated coefficients for all the interaction variables. The F-statistic is comfortably above 30 for the estimates in column (1) which suggests that the full set of the interaction variables are suitable instruments to estimate the effects of total farm income on household consumption ${ }^{18}$ (As described below, the estimates in columns (2), (3) and (4) are used to construct measures of rainfall shocks but not for 2SLS estimation).

The second-stage results are shown in Table 12. Columns (1)-(3) in Panel A provide the estimated effects of shocks to household income on total food consumption for, respectively, all households, nuclear family households and extended family households, based on the first-stage estimation in Table 11, column (1). We do tests of over-identification for each sample and report the Hansen J-statistics and p-values in the last two rows of Table 12, Panel A. The over-identification restrictions are satisfied in each case $\ell^{19}$. The second-stage estimates indicate that a $10 \%$ change in income induced by rainfall shocks leads to a $1.9 \%$ change in consumption in the full sample. For nuclear and extended family households, the corresponding changes in consumption are $3.7 \%$ and $1.2 \%$, respectively. A test of the equality of the two coefficients is rejected at the $1 \%$ level. Therefore, it is apparent that food consumption in extended households is less exposed to idiosyncratic shocks than food consumption in nuclear family households.

To implement the non-linear Wald test described in (19), we construct alternative measures of rainfall shocks using the predicted values of log of household income based on the estimates in Table 11, columns 2-4. Each of these measures of rainfall shocks capture the effects of rainfall on income via plots of a specific ownership category - collective, male private and female private. Columns 4-6 of Table 12, Panel A reports the estimated effects of these different measures of rainfall shocks on total food consumption ${ }^{20}$ The corresponding estimates for sub-categories of food consumption - home-grown cereals, other home-grown produce, and purchased food - are shown in columns (1)-(9), panel B. The $\chi_{2}$-statistics for the non-linear Wald tests are provided in Table 10 . We are able to reject consumption efficiency for the full sample of households at the $1 \%$ signifance level and for the sample of extended-family households at the $7 \%$ significance level. However, we are not able to reject consumption efficiency for the sample of nuclear family households.

\subsection{Idiosyncratic Income Shocks and Child Anthropometrics}

In this section, we provide direct evidence on whether co-resident household members share idiosyncratic income risk. Intuitively, household members who experience negative income draws

\footnotetext{
${ }^{18}$ In the Appendix Table A1, we reproduce the estimates shown in Table 11 for nuclear family and extended family households separately and the results are broadly consistent with those shown in Table 11.

${ }^{19}$ Notice that in addition to crop income, our measure of income also includes livestock sales and non-farm income. Taking into account income from the last two sources makes it less likely that rainfall could affect consumption through other channels than income.

${ }^{20}$ Note that each coefficient in Table 12, Panel A, columns 4-6 corresponds to a different regression.
} 
may benefit from transfers from co-resident individuals so that, on average, controlling for household aggregate shocks, individual consumption is insulated from own shocks. Ideally, implementing such a test would require measures of individual level consumption or nutrition as used by Dercon and Krishnan (2000) to test-risk sharing within households in Ethiopia. In this paper we use childlevel anthropometric outcomes, namely standardised child mid-upper-arm-circumference (MUAC). During each round of the survey, all children below the age of 5 had their MUAC measured twice: in July and in December, that correspond, respectively, to the peak of the lean season and the harvest period. MUAC is a simple method of assessing nutritional status in children aged 6 to 60 months recommended by the World Health Organization (WHO) as an independent criterion for screening young children for nutrition programming (Emergency Nutrition Network, 2012; Goossens et al., 2012).

If households are efficiently sharing risk, then exogenous shocks to a mother's income should not influence nutritional outcomes for her children, once household-level aggregate shocks have been controlled for. Based on this intuition, we estimate the following equation for the full sample of households, and separately for nuclear and extended family households:

$$
M U A C_{i j h t}=\pi_{m} \hat{y}_{j h t}+\mathbf{X}_{i j h v t} \boldsymbol{\zeta}_{m}+\lambda_{h t}+\nu_{i j h t}
$$

where $M U A C_{i j h t}$ is the z-score of the upper-arm circumference of child $i$ with mother $j$ in household $h$ in period $t ; \hat{y}_{j h t}$ is a measure of $j$ 's individual farm income or food consumption expenditures as described below; the vector $\mathbf{X}_{i j h v t}$ includes the characteristics of the child including, age and gender; $\lambda_{h t}$ denotes household-year fixed-effects; and $\nu_{i j h t}$ is an error term. In the econometric estimations, we use both the measures taken in July and in December, and control for the month in which the measure was taken. Arguably, using both measures reduces measurement errors in MUAC. We include the household-year fixed effects in order to control for household level shocks. Note that, due to the inclusion of these fixed-effects, the sample can only include households which have multiple mothers. In the case of nuclear family households, this translates into the sub-sample of households where the head is polygynous. Perfect risk-sharing within the household would mean that $\pi_{m}=0$.

We report the estimation results in Table 11. Columns 1-3 investigate the effects of exogenous shocks to the mother's crop income and columns 4-6 focus on the effects of mother food consumption expenditures 21 Mother's food consumption expenditures are measured as the sum of mother's harvest used in auto-consumption and food purchases by the mother - the purchases are financed by crop sales and non-farm income. We use the mother's plot characteristics interacted with local rainfall deviations to instrument for the mother's income and food consumption expenditures. The F-statistics of excluded instruments shown in the penultimate row are all comfortably above the

\footnotetext{
${ }^{21}$ We use the mother's crop income and food consumption expenditures for the current year rather than lagged variables as MUAC is known to respond quickly to changes in nutrition (Goossens et al., 2012, 2013) and food consumption patterns during a particular agricultural cycle may respond to rainfall realisations even before the harvest in anticipation of changes in future income.
} 
10 with the exception of column 5. Therefore, it is unlikely that the results are driven by weak instruments.

The results in columns 1-3 indicate that controlling for household level-shocks, shocks to the mother's income are passed through to child nutritional outcomes in the full sample (column 1) and in extended family households (column 2), although the effects are relatively small. In nuclear family households, however, the point estimate is virtually zero (column 3) implying that child nutritional outcomes are unaffected by shocks to mother's income once household-level shocks are controlled for. We obtain a similar pattern in the rejection of intra-household insurance when we use mother's food expenditures in columns 4-6, except that the point estimates are larger: the hypothesis of full insurance is rejected for the full sample and extended family households in columns 1 and 2, but not for nuclear family households in columns 3 .

Overall, the results suggest that nuclear family households are pooling risk but extended family households are not with respect to the nutrition of children.

\section{Robustness Checks}

As noted in section 4, the characteristics of nuclear and extended-family households differ along a number of dimensions which can affect the pattern of resource allocation within them. Extendedfamily households, on average, have more members, the head is, on average, older and more likely to be polygynous. It is plausible that the source of observed inefficiency of extended-family households is not due to the nature of ties between the household members, per se, but due to their larger size, or the practice of polygyny or the natural life-cycle of the household. To explore these hypotheses, we replicate the basic test of efficiency in production and consumption, as described in sections 5 and 6. for subsets of the household sample which are identical or similar along these dimensions.

Specifically, we consider three subsamples: (i) the subset of monogamous households; (ii) a subset of households for which the size distribution is nearly identical for nuclear and extendedfamily households; (iii) a subset of households for which the distribution of the head's age is nearly identical for nuclear and extended-family households. For (ii) and (iii), we perform a logit regression of the binary variable 'nuclear family household' on household size and head's age, and then retain nuclear and extended family households with close predicted probabilities. In the resulting subsample for (ii), average household size is 7.67 for extended family households and 7.65 for nuclear family households and the two means are statistically indistinguishable. In the resulting subsample for (iii), average household head age is 45.48 years for extended family households and 45.60 years for nuclear family households and, again, the two means are statistically indistinguishable. Arguably, any differences we detect between the nuclear and extended family households within these subsamples are not due to differences in household size in (ii), or differences in the age of the household head in (iii).

In Table 12, we report estimates of the basic plot yield equation in (13) for the subset of 
monogamous households (columns 1-3), the age-based subsample (columns 4-6) and the size-based subsample (columns 7-9). We find that the estimated coefficients for male and female private plots in nuclear and extended-family households are close to those obtained using the full sample of households. In particular, the households achieve lower yields on private plots compared to collective plots (the excluded plot category), and the yield gaps are higher for extended family households than for nuclear family households. For each subsample, we can reject a null hypothesis of equality in the female plot coefficients across nuclear and extended family households. Similarly, we can reject the null hypothesis of equality of the corresponding male plot coefficients. Therefore, we conclude that the wider dispersion of plot yields across extended family households cannot be attributed to the extent of polygyny, household size or the household life-cycle as captured by the age of the head.

To investigate the extent of consumption risk-sharing for these subsamples, we re-estimate equations (16)-(18) and replicate the non-linear Wald test for equation (19) using each set of estimates. The Wald statistic and p-values are reported in Table 13. The tests imply a rejection of efficient risk-sharing for the subsamples based on household size and the head's age at the 5\% significance level and for the monogamous subsample at the $10 \%$ signficance level. In each case, we fail to reject consumption efficiency for the nuclear family households. We also fail to reject efficiency for the extended family households for two out of the three subsamples but the Wald statistics are consistently larger than in the case of nuclear family households. It is possible that the failure to reject for the extended family households in these two cases is due to sample size issues.

Although not conclusive, these patterns are broadly consistent with the results obtained for the full sample of households. The rejection of consumption efficiency in the full sample does not appear to be driven by polygyny given that rejection also occurs for the subsample of monogamous households 22

\section{Alternative Theories}

Next, we consider whether alternative explanations of intra-household inefficiency in the literature can explain our empirical results, in particular limited commitment (e.g. Ligon 2002; Mazzocco 2007), informational asymmetry (e.g. Ashraf 2009), preference heterogeneity (e.g. Foster and Rosenzweig 2002), and moral hazard in teams (Guirkinger and Platteau 2015; Guirkinger et al. 2015), and how our proposed theory is related to them.

First, we note that lack of commitment is central to the theory we develop: the household head (or any other plot owner) cannot, ex-ante, commit to rewarding other household members

\footnotetext{
${ }^{22}$ Akresh, Chen and Moore (2016) provide a potential explanation for why intra-household efficiency would differ between monogamous and polygynous households. But their explanation implies that monogamous households would be less efficient while our tests of consumption efficiency imply that, within the subsample of extended-family households, they are more efficient.
} 
for their labour on farm plots. If it were possible to do so, the household could implement labour contracts that lead to an efficient allocation of intra-household labour. With regard to information, we assume only the visibility of plot incomes and whether proceeds from collective plots have been used in accordance with social norms; in particular, the theory is consistent with the notion of workers' farm labour being imperfectly observed by plot owners.

Therefore, if we shut down altruism in the model - i.e. $\delta_{i j}=\delta_{j i}=0$ - we obtain a household characterised by lack of commitment and, potentially, informational asymmetry and preference heterogeneity regarding household public goods. Then, we can still obtain differences in labour intensity and plot yields between collective plots and private plots, with these gaps being more favourable to the collective plot when household members exhibit stronger preference for the household public good. However, to reconcile the empirical results with these theoretical predictions in the absence of altruism, we would have to assume that individuals in nuclear family households have weaker preferences for the goods on which expenditures are made with the proceeds from the collective plots. This seems unlikely given that non-nuclear households contain a more varied group of individuals with, potentially, more diverse preferences regarding household expenditures.

Yield gaps between collective plots and private plots can also emerge due to moral hazard in teams, as shown theoretically by Guirkinger and Platteau (2015) and empirically tested for households in rural Mali by Guirkinger et al. (2015). However, this mechanism results in lower yields on collective plots as compared to private plots while we obtain the opposite result for our sample of nuclear and extended-family households in Burkina Faso.

Thus, we conclude that it is difficult to account for our empirical results on the basis of alternative theories of intra-household inefficiency where family ties play no role. An alternative theory of intra-household allocation where family ties can play an important role is provided by Akresh, Chen and Moore (2016). They postulate that resource allocation is based on a cooperative agreement sustained by the threat of non-cooperation (by contrast, we postulate that the equilibrium allocation is a non-cooperative equilibrium). In this setting, the gains from cooperation are decreasing in the level of altruism such that it is more difficult to sustain cooperation when intra-household altruism is higher. In the context of our analysis, if nuclear family households have higher levels of altruism than non-nuclear households, their theory would imply that extended-family households are more efficient. However, we find the opposite is true in our empirical analysis.

\section{The Advantages of Extended-Family Households}

In sections 5 5.2, we provide evidence that nuclear family households allocate resources more efficiently than extended family households, and that, within the same household, there is higher transfer of labour resources between individuals who share a nuclear family tie. Yet, more than half the households in our sample of rural Burkinabe households are extended-family households. Data from the Demographic and Health Surveys indicates that between one-quarter and three- 
quarter of households in West African countries, are extended-family households (Kazianga and Wahhaj 2016). Given the advantages of nuclear family households, there is a need to explain why we see such a high prevalence of extended family households across West Africa and, in particular, in Burkina Faso.

We posit and present evidence on two broad explanations, both related to market failure. In the context of Burkina Faso, the household head does not have the freedom to sell the farmland that he inherits from the lineage. The presence of market failure in land rental and labour markets prevents him from renting out this land or hiring in labour to work on it (see, for example, Udry 1996, and the references within). However, the institution of a household allows him to commit to using the proceeds of the household collective plots on household public goods and, thus, incentivise farm labour effort from any individual who joins the household, as well as remunerate these extra working hands by awarding them individual farming plots to work on. A household head who starts off with a large quantity of inherited land in relation to the size of his nuclear family will calculate a higher marginal product of labour of an additional individual that he can persuade to join the household 23 . Therefore, controlling for the size of the nuclear family, a household head with a large quantity of inherited land should have a higher net benefit from - and therefore be more likely to have - extended-family members or unrelated individuals living within his household.

To test this hypothesis, we estimate linear probability models where the dependent variable is the household structure $(1=$ nuclear, $0=$ extended $)$, and include the head's inherited land, and the demographic composition of his nuclear family as explanatory variables. The results are shown in Table 17. We also control for the household's other farmland (columns 1-3) or the household's total land per capita (columns 4-6). In columns 6-9, we include the squared term of inherited land to check for non-linearity in the hypothesized relationship. The specifications also include year dummies (columns 1, 4 and 7), year dummies and village fixed-effects (columns 2,5 and 8), or village-year fixed-effects (columns 3,6 and 9). In each estimation, the probability of an extendedfamily household is increasing in the size of the head's inherited land (statistically significant at the $1 \%$ level), as implied by the hypothesis described above.

Our second explanation relates to financial market failure. The income volatility of agricultural households in developing countries, the challenges they face in obtaining credit and insurance from the market for the purpose of consumption smoothing, and the limited nature of informal insurance within villages have been well documented in the literature (e.g. Townsend, 1994; Dercon 2002; Kazianga and Udry, 2006). In this context, increasing the size of the household by having non-nuclear members join it can help the household to diversify its income sources and therefore improve consumption smoothing. The estimates in Table 13 - discussed in Section 6.1.1 - shows that household food consumption is more sensitive to shocks to agricultural income in the case of

\footnotetext{
${ }^{23}$ It is important to note that the head's nuclear family size is also endogenous since this is determined by marriage decisions (monogamy versus polygyny) and fertility choice. However, these choices can only provide a long-term solution to the household's farm labour shortages. By contrast, the household's available labour can be adjusted relatively quickly by having extended-family members or unrelated individuals join or leave the household.
} 
nuclear family households than in the case of extended family households, point estimate of 0.334 versus 0.158 , and statistically different at the $5 \%$ level.

We provide an indirect test of this hypothesis relating to financial market failure using historical rainfall data to create a measure of a household's income volatility. Specifically, we use the estimated coefficients from the first-stage regressions in Table 11, information on the characteristics of the head's inherited land, and data on historical rainfall to calculate the household's predicted income shocks during the 20 year period prior to the survey. We take the variance of these income shocks to construct a measure of each household head's income volatility when he first inherited his land as a function of the farmland characteristics and local rainfall conditions. The hypothesis related to financial market failure would imply that household heads facing greater income volatility should be more likely to have extended-family members or unrelated individuals living within his household.

In Table 18, we present estimates of linear probability models of household structure similar to those in Table 16 but include the head's income volatility as an explanatory variable. Consistent with our reasoning, increased volatility increases the probability of an extended-family household, the relevant coefficient being statistically significant at the $1 \%$ level for each specification. In other words, household heads exposed to greater income volatility due to the characteristics of their inherited land and local rainfall conditions were more likely to end up with extended-family households.

\section{Conclusion}

In this paper, we investigated and compared how resources are allocated within nuclear and extended-family households in rural Burkina Faso. We found that nuclear family households are close to being efficient in household production, and could not reject the hypothesis that they engaged in efficient intra-household risk-sharing in consumption choices. By contrast, extended family households were found to be inefficient in both production and consumption choices.

We argued that these differences were due to the stronger familial ties that exist within the nuclear family. In support of this hypothesis we showed that labour contributions by household members on individually managed plots were significantly higher when the owner and worker shared a nuclear family tie, as compared to the situation where they shared an extended family tie or were unrelated.

These results are significant for the wider literature on intra-household allocation and household composition. First, we identify within the same geographic, economic and social environments two sets of households, one which achieves near Pareto efficiency in production and consumption decisions and another which does not. We developed a theory of intra-household allocation where we explicitly account for familial ties and account for both efficient and inefficient production and consumption choices. The empirical evidence, combined with the theory, provides a way of reconciling two strands of empirical evidence in the literature that have either failed to reject or 
have rejected Pareto efficient allocation of household resources.

It is important to recognise that the composition of a household - in particular, whether it consists of a nuclear family unit or includes extended family members and unrelated individuals is endogenous to the migration decisions of its members. Therefore, differences in intra-household allocation between nuclear and extended-family households may be due, at least in part, to selection effects. In our analysis we do not isolate or rule out this potential source of variation.

Nevertheless, the evidence on the more efficient nature of nuclear family households raises the question why extended family households exist at all. We presented two hypotheses related to (i) land and labour market failure and (ii) insurance market failure, and presented evidence consistent with these explanations. The implication is that the development of these markets in similar rural settings, combined with increasing land scarcity, will cause extended family households to give way to nuclear family households. In the context of small-holder agricultural households, the analysis suggests that the evolution of household composition from extended to nuclear family households will lead to more efficient allocation of productive resources within the household because of the ties that bind together members of the nuclear family.

\section{Theoretical Appendix}

Deriving Conditions for Labour Allocation: From the optimisation problem in (5) for a male household member $i$, and the demand equations in section (3.1), we obtain the following first-order conditions:

$$
\begin{aligned}
\frac{\partial F\left(q_{j}, A_{j}, L_{m j}, L_{f j}, \mathbf{r}\right)}{\partial L_{m j}} \sum_{p=1}^{\bar{p}} U_{j p}^{i}\left(\Lambda_{v}\right)^{-1} \zeta_{p v} & =\frac{\partial F\left(q_{c}, A_{c}, L_{m c}, L_{f c}, \mathbf{r}\right)}{\partial L_{m c}}\left[U_{z}^{i}\left(\Lambda^{-1}\right)+\sum_{k \in \mathcal{I}_{z}} \sum_{p=1}^{\bar{p}} U_{k p}^{i}\left(\Lambda^{-1}\right) \zeta_{k p c}\right] \\
\text { for each } j & \in \mathcal{I}-\mathcal{I}_{z}
\end{aligned}
$$

Using the functional forms for production and utility, we can write $\frac{\partial F\left(q_{j}, A_{j}, L_{m j}, L_{f j}, \mathbf{r}\right)}{\partial L_{m j}}=\beta_{1} \frac{F\left(q_{j}, A_{j}, L_{m j}, L_{f j}, \mathbf{r}\right)}{L_{m j}}$ and $U_{j p}^{i}=\delta_{i j} \delta_{p v}\left(x_{j p}\right)^{\rho-1} \frac{U^{i}(.)}{\left[U^{i}(.)\right]^{\rho}}$. Hence we obtain

$$
\begin{aligned}
& \beta_{1} \frac{F\left(q_{j}, A_{j}, L_{m j}, L_{f j}, \mathbf{r}\right)}{L_{m j}} \sum_{p=1}^{\bar{p}} \delta_{i j} \delta_{p v}\left(x_{j p}\right)^{\rho-1}\left(\Lambda_{v}\right)^{-1} \zeta_{p v} \frac{U^{i}(.)}{\left[U^{i}(.)\right]^{\rho}} \\
= & \beta_{1} \frac{F\left(q_{c}, A_{c}, L_{m c}, L_{f c}, \mathbf{r}\right)}{L_{m c}}\left[\delta_{i c}(z)^{\rho-1} \frac{U^{i}(.)}{\left[U^{i}(.)\right]^{\rho}}\left(\Lambda^{-1}\right)+\sum_{k \in \mathcal{I}_{z}} \sum_{p=1}^{\bar{p}} \delta_{i k} \delta_{p v}\left(x_{k p}\right)^{\rho-1}\left(\Lambda^{-1}\right) \zeta_{k p c} \frac{U^{i}(.)}{\left[U^{i}(.)\right]^{\rho}}\right]
\end{aligned}
$$

Simplifying this last equation, we obtain

$$
\delta_{i j} \frac{v\left(\mathbf{x}_{j}\right)}{L_{m j}}=\hat{\delta}_{i c} \frac{\left(y_{z}\right)^{\rho}}{L_{m c}}
$$

where $\hat{\delta}_{i c}=\left(\frac{y_{c}}{\bar{y}_{z}}\right)\left[\delta_{i c}+\sum_{k \in \mathcal{I}_{z}} \sum_{p=1}^{\bar{p}} \delta_{i k} \delta_{p v}\left(\zeta_{k p c}\right)^{\rho}\right]$. Similarly, for a female household member $j$, we obtain

$$
\delta_{j i} \frac{v\left(\mathbf{x}_{i}\right)}{L_{f j}}=\hat{\delta}_{j c} \frac{\left(y_{z}\right)^{\rho}}{L_{f c}}
$$


More generally, for two household members $i$ (male) and $j$ (female) we can write:

$$
\begin{aligned}
& \hat{\delta}_{i c} \frac{\left(y_{z}\right)^{\rho}}{L_{m c}}=\frac{v\left(\mathbf{x}_{i}\right)}{L_{m i}}=\delta_{i j} \frac{v\left(\mathbf{x}_{j}\right)}{L_{m j}} \\
& \hat{\delta}_{j c} \frac{\left(y_{z}\right)^{\rho}}{L_{f c}}=\delta_{j i} \frac{v\left(\mathbf{x}_{i}\right)}{L_{f i}}=\frac{v\left(\mathbf{x}_{j}\right)}{L_{f j}}
\end{aligned}
$$

Dividing each term in 21) by the corresponding term in (22), we obtain

$$
\frac{\hat{\delta}_{i c}}{\hat{\delta}_{j c}} \frac{L_{f c}}{L_{m c}}=\frac{1}{\delta_{j i}} \frac{L_{f i}}{L_{m i}}=\delta_{i j} \frac{L_{f j}}{L_{m j}}
$$

Let $\frac{\hat{\delta}_{i c}}{\hat{\delta}_{j c}} \frac{L_{f c}}{L_{m c}}=R$. Then $\frac{L_{f i}}{L_{m i}}=\delta_{j i} R$ and $\frac{L_{f j}}{L_{m j}}=\frac{1}{\delta_{i}} R$. For ease of notation, we let $\tilde{A}_{j}=$ $\left\{R\left(q_{j}, \mathbf{r}\right)\right\}^{\frac{1}{\alpha}}\left(A_{j}\right)$. Then output from the collective plot can be written as

$$
\begin{aligned}
&\left(\tilde{A}_{c}\right)^{\alpha}\left(L_{m c}\right)^{\beta_{1}}\left(L_{f c}\right)^{\beta_{2}} \\
&=\left(\tilde{A}_{c}\right)^{\alpha}\left(L_{m c}\right)^{\beta_{1}}\left(\frac{\hat{\delta}_{j c}}{\hat{\delta}_{i c}} R L_{m c}\right)^{\beta_{2}} \\
&=\left(\frac{\hat{\delta}_{j c}}{\hat{\delta}_{i c}} R\right)^{\beta_{2}}\left(\tilde{A}_{c}\right)^{\alpha}\left(L_{m c}\right)^{\beta_{1}+\beta_{2}} \\
& \Longrightarrow \frac{\left(y_{c}\right)^{\rho}}{L_{m c}}=\left(\frac{\hat{\delta}_{j c}}{\hat{\delta}_{i c}} R\right)^{\rho \beta_{2}}\left(\tilde{A}_{c}\right)^{\rho \alpha}\left(L_{m c}\right)^{\rho\left(\beta_{1}+\beta_{2}\right)-1}
\end{aligned}
$$

Similarly,

$$
\begin{aligned}
\frac{v\left(\mathbf{x}_{i}\right)^{\rho}}{L_{m i}} & =\left(\delta_{j i} R\right)^{\rho \beta_{2}}\left(\tilde{A}_{i}\right)^{\rho \alpha}\left(L_{m i}\right)^{\rho\left(\beta_{1}+\beta_{2}\right)-1} \\
\frac{v\left(\mathbf{x}_{j}\right)^{\rho}}{L_{m j}} & =\left(\frac{1}{\delta_{i j}} R\right)^{\rho \beta_{2}}\left(\tilde{A}_{j}\right)^{\rho \alpha}\left(L_{m j}\right)^{\rho\left(\beta_{1}+\beta_{2}\right)-1}
\end{aligned}
$$

Substituting for these terms into (??), we obtain

$$
\begin{aligned}
\hat{\delta}_{i c}\left(\frac{\hat{\delta}_{j c}}{\hat{\delta}_{i c}} R\right)^{\rho \beta_{2}}\left(\tilde{A}_{c}\right)^{\rho \alpha}\left(L_{m c}\right)^{\rho\left(\beta_{1}+\beta_{2}\right)-1} & =\left(\delta_{j i} R\right)^{\rho \beta_{2}}\left(\tilde{A}_{i}\right)^{\rho \alpha}\left(L_{m i}\right)^{\rho\left(\beta_{1}+\beta_{2}\right)-1} \\
& =\delta_{i j}\left(\frac{1}{\delta_{i j}} R\right)^{\rho \beta_{2}}\left(\tilde{A}_{j}\right)^{\rho \alpha}\left(L_{m j}\right)^{\rho\left(\beta_{1}+\beta_{2}\right)-1} \\
& \Longrightarrow\left(\hat{\delta}_{i c}\right)^{1-\rho \beta_{2}}\left(\hat{\delta}_{j c}\right)^{\rho \beta_{2}}\left(\tilde{A}_{c}\right)^{\rho \alpha}\left(L_{m c}\right)^{\rho\left(\beta_{1}+\beta_{2}\right)-1} \\
& =\left(\delta_{j i}\right)^{\rho \beta_{2}}\left(\tilde{A}_{i}\right)^{\rho \alpha}\left(L_{m i}\right)^{\rho\left(\beta_{1}+\beta_{2}\right)-1} \\
& =\left(\delta_{i j}\right)^{1-\rho \beta_{2}}\left(\tilde{A}_{j}\right)^{\rho \alpha}\left(L_{m j}\right)^{\rho\left(\beta_{1}+\beta_{2}\right)-1}
\end{aligned}
$$


Taking logs and multiplying throughout by -1 , we obtain

$$
\begin{aligned}
& -\left(1-\rho \beta_{2}\right) \ln \left(\hat{\delta}_{i c}\right)-\rho \beta_{2} \ln \left(\hat{\delta}_{j c}\right)-\rho \alpha \ln \tilde{A}_{c}+\left[1-\rho\left(\beta_{1}+\beta_{2}\right)\right] \ln L_{m c} \\
= & -\rho \beta_{2} \ln \left(\delta_{j i}\right)-\rho \alpha \ln \left(\tilde{A}_{i}\right)+\left[1-\rho\left(\beta_{1}+\beta_{2}\right)\right] \ln L_{m i} \\
= & -\left(1-\rho \beta_{2}\right) \ln \left(\delta_{i j}\right)-\rho \alpha \ln \left(\tilde{A}_{j}\right)+\left[1-\rho\left(\beta_{1}+\beta_{2}\right)\right] \ln L_{m j}
\end{aligned}
$$

Therefore, using (24) and (25), we obtain

$$
\begin{aligned}
& {\left[1-\rho\left(\beta_{1}+\beta_{2}\right)\right] \ln L_{m c}-\left[1-\rho\left(\beta_{1}+\beta_{2}\right)\right] \ln L_{m i}=\rho \alpha \ln \left(\frac{\tilde{A}_{c}}{\tilde{A}_{i}}\right)+\left(1-\rho \beta_{2}\right) \ln \left(\hat{\delta}_{i c}\right)} \\
& +\rho \beta_{2}\left[\ln \left(\hat{\delta}_{j c}\right)-\ln \left(\delta_{j i}\right)\right] \\
& \Longrightarrow\left[1-\rho\left(\beta_{1}+\beta_{2}\right)\right] \ln \left(\frac{L_{m c}}{A_{c}}\right)-\left[1-\rho\left(\beta_{1}+\beta_{2}\right)\right] \ln \left(\frac{L_{m i}}{A_{i}}\right) \\
& =-\left[1-\rho\left(\beta_{1}+\beta_{2}\right)\right] \ln \left(\frac{A_{c}}{A_{i}}\right)+\rho \alpha \ln \left(\frac{\tilde{A}_{c}}{\tilde{A}_{i}}\right)+\left(1-\rho \beta_{2}\right) \ln \left(\hat{\delta}_{i c}\right)+\rho \beta_{2}\left[\ln \left(\hat{\delta}_{j c}\right)-\ln \left(\delta_{j i}\right)\right] \\
& \Longrightarrow\left[1-\rho\left(\beta_{1}+\beta_{2}\right)\right] \ln \left(\frac{L_{m c}}{A_{c}}\right)-\left[1-\rho\left(\beta_{1}+\beta_{2}\right)\right] \ln \left(\frac{L_{m i}}{A_{i}}\right) \\
& =\left[\rho\left(\alpha+\beta_{1}+\beta_{2}\right)-1\right] \ln \left(\frac{A_{c}}{A_{i}}\right)+\rho \ln \left[\frac{R_{c}\left(q_{c}, \mathbf{r}\right)}{R_{i}\left(q_{i}, \mathbf{r}\right)}\right]+\left(1-\rho \beta_{2}\right) \ln \left(\delta_{i c}\right)+\rho \beta_{2}\left[\ln \left(\delta_{j c}\right)-\ln \left(\delta_{j i}\right)\right]
\end{aligned}
$$

Therefore,

$$
\begin{aligned}
\ln \left(\frac{L_{m c}}{A_{c}}\right)-\ln \left(\frac{L_{m i}}{A_{i}}\right)= & {\left[\frac{\rho\left(\alpha+\beta_{1}+\beta_{2}\right)-1}{1-\rho\left(\beta_{1}+\beta_{2}\right)}\right] \ln \left(\frac{A_{c}}{A_{i}}\right)+\frac{\rho}{\left[1-\rho\left(\beta_{1}+\beta_{2}\right)\right]} \ln \left[\frac{R_{c}\left(q_{c}, \mathbf{r}\right)}{R_{i}\left(q_{i}, \mathbf{r}\right)}\right] } \\
& +\left[\frac{1-\rho \beta_{2}}{1-\rho\left(\beta_{1}+\beta_{2}\right)}\right] \ln \left(\hat{\delta}_{i c}\right)+\left[\frac{\rho \beta_{2}}{1-\rho\left(\beta_{1}+\beta_{2}\right)}\right]\left[\ln \left(\hat{\delta}_{j c}\right)-\ln \left(\delta_{j i}\right)\right]
\end{aligned}
$$

Following a similar reasoning, we have

$$
\begin{aligned}
\ln \left(\frac{L_{m c}}{A_{c}}\right)-\ln \left(\frac{L_{m j}}{A_{j}}\right)= & {\left[\frac{\rho\left(\alpha+\beta_{1}+\beta_{2}\right)-1}{1-\rho\left(\beta_{1}+\beta_{2}\right)}\right] \ln \left(\frac{A_{c}}{A_{j}}\right)+\frac{\rho}{\left[1-\rho\left(\beta_{1}+\beta_{2}\right)\right]} \ln \left[\frac{R_{c}\left(q_{c}, \mathbf{r}\right)}{R_{j}\left(q_{j}, \mathbf{r}\right)}\right] } \\
& +\left[\frac{\rho \beta_{2}}{1-\rho\left(\beta_{1}+\beta_{2}\right)}\right] \ln \left(\hat{\delta}_{j c}\right)+\left[\frac{1-\rho \beta_{2}}{1-\rho\left(\beta_{1}+\beta_{2}\right)}\right]\left[\ln \left(\hat{\delta}_{i c}\right)-\ln \left(\delta_{i j}\right)\right] \\
\ln \left(\frac{L_{f c}}{A_{c}}\right)-\ln \left(\frac{L_{f j}}{A_{j}}\right)= & {\left[\frac{\rho\left(\alpha+\beta_{1}+\beta_{2}\right)-1}{1-\rho\left(\beta_{1}+\beta_{2}\right)}\right] \ln \left(\frac{A_{c}}{A_{j}}\right)+\frac{\rho}{\left[1-\rho\left(\beta_{1}+\beta_{2}\right)\right]} \ln \left[\frac{R_{c}\left(q_{c}, \mathbf{r}\right)}{R_{j}\left(q_{j}, \mathbf{r}\right)}\right](29) } \\
\ln \left(\frac{L_{f c}}{A_{c}}\right)-\ln \left(\frac{L_{f i}}{A_{i}}\right)= & {\left[\frac{1-\rho \beta_{1}}{1-\rho\left(\beta_{1}+\beta_{2}\right)}\right] \ln \left(\hat{\delta}_{j c}\right)+\left[\frac{\rho \beta_{1}}{1-\rho\left(\beta_{1}+\beta_{2}\right)}\right]\left[\ln \left(\hat{\delta}_{i c}\right)-\ln \left(\delta_{i j}\right)(30)\right.} \\
+ & {\left[\frac{\left.\rho \beta_{1}+\beta_{2}\right)-1}{1-\rho\left(\beta_{1}+\beta_{2}\right)}\right] \ln \left(\frac{A_{c}}{A_{i}}\right)+\frac{\rho}{\left[1-\rho\left(\beta_{1}+\beta_{2}\right)\right]} \ln \left[\frac{R_{c}\left(q_{c}, \mathbf{r}\right)}{R_{i}\left(q_{i}, \mathbf{r}\right)}\right](31) }
\end{aligned}
$$


Using $\left(\alpha+\beta_{1}+\beta_{2}\right)=1$, we obtain the equations shown in (10) and 11).

Deriving Conditions for Plot Yields: By construction, we have

$$
\begin{aligned}
& \ln \left(\frac{y_{c}}{A_{c}}\right)=\ln R_{c}\left(q_{c}, \mathbf{r}\right)+\left(\alpha+\beta_{1}+\beta_{2}-1\right) \ln \left(A_{c}\right)+\beta_{1} \ln \left(\frac{L_{m c}}{A_{c}}\right)+\beta_{2} \ln \left(\frac{L_{f c}}{A_{c}}\right) \\
& \ln \left(\frac{y_{i}}{A_{i}}\right)=\ln R_{i}\left(q_{i}, \mathbf{r}\right)+\left(\alpha+\beta_{1}+\beta_{2}-1\right) \ln \left(A_{i}\right)+\beta_{1} \ln \left(\frac{L_{m i}}{A_{i}}\right)+\beta_{2} \ln \left(\frac{L_{f i}}{A_{i}}\right)
\end{aligned}
$$

Therefore,

$$
\begin{aligned}
\ln \left(\frac{y_{c}}{A_{c}}\right)-\ln \left(\frac{y_{i}}{A_{i}}\right)= & \ln \left[\frac{R_{c}\left(q_{c}, \mathbf{r}\right)}{R_{i}\left(q_{i}, \mathbf{r}\right)}\right]+\left(\alpha+\beta_{1}+\beta_{2}-1\right) \ln \left(\frac{A_{c}}{A_{i}}\right) \\
& +\beta_{1}\left[\ln \left(\frac{L_{m c}}{A_{c}}\right)-\ln \left(\frac{L_{m i}}{A_{i}}\right)\right] \\
& +\beta_{2}\left[\ln \left(\frac{L_{f c}}{A_{c}}\right)-\ln \left(\frac{L_{f i}}{A_{i}}\right)\right]
\end{aligned}
$$

Substituting into (33) using (27) and (32), we obtain

$$
\begin{aligned}
\ln \left(\frac{y_{c}}{A_{c}}\right)-\ln \left(\frac{y_{i}}{A_{i}}\right)= & \Gamma^{\prime} \ln \left[\frac{R_{c}\left(q_{c}, \mathbf{r}\right)}{R_{i}\left(q_{i}, \mathbf{r}\right)}\right]+\Gamma \ln \left(\frac{A_{c}}{A_{i}}\right)+\left[\frac{\beta_{1}}{1-\rho\left(\beta_{1}+\beta_{2}\right)}\right] \ln \left(\hat{\delta}_{i c}\right) \\
& +\left[\frac{\beta_{2}}{1-\rho\left(\beta_{1}+\beta_{2}\right)}\right]\left[\ln \left(\hat{\delta}_{j c}\right)-\ln \left(\delta_{j i}\right)\right]
\end{aligned}
$$

where $\Gamma=(\alpha-1)+\left(\beta_{1}+\beta_{2}\right)\left[\frac{\alpha \rho}{1-\rho\left(\beta_{1}+\beta_{2}\right)}\right], \Gamma^{\prime}=1+\frac{\rho}{\left[1-\rho\left(\beta_{1}+\beta_{2}\right)\right]}$.

Similarly, we can show that

$$
\begin{aligned}
\ln \left(\frac{y_{c}}{A_{c}}\right)-\ln \left(\frac{y_{j}}{A_{j}}\right)= & \Gamma^{\prime} \ln \left[\frac{R_{c}\left(q_{c}, \mathbf{r}\right)}{R_{j}\left(q_{j}, \mathbf{r}\right)}\right]+\Gamma \ln \left(\frac{A_{c}}{A_{j}}\right)+\left[\frac{\beta_{2}}{1-\rho\left(\beta_{1}+\beta_{2}\right)}\right] \ln \left(\hat{\delta}_{j c}\right) \\
& +\left[\frac{\beta_{1}}{1-\rho\left(\beta_{1}+\beta_{2}\right)}\right]\left[\ln \left(\hat{\delta}_{i c}\right)-\ln \left(\delta_{i j}\right)\right]
\end{aligned}
$$

Using $\left(\alpha+\beta_{1}+\beta_{2}\right)=1$, we obtain the equations shown in (8) and (9).

Individual Labour Contributions on Plots: Let us denote by $\mu_{i j}$ the fraction of total labour on plot $j$ provided by worker $i ; \mu_{i j}$ is likely to depend on $i$ 's own characteristics that shape, for example, his bargaining power within the household and suitability for farm work ${ }^{24}$ We let $\mu_{i i}=\frac{\mu_{i}}{n_{m}(i)}, \mu_{i j}=\frac{\mu_{i}}{n_{m}(j)} \mu\left(\mathbf{w}_{i}\right)$ where $n_{m}(j)$ is the total number of male workers on plot $j$ and $\mathbf{w}_{i}$ is a vector of individual characteristics of worker $i$. If $\mu_{i}=\mu\left(\mathbf{w}_{i}\right)=1$, then work would be divided equally between workers on each plot. Thus, $\mu_{i}$ is the extent to which $i$ 's labour share on his own plot deviates from equal shares, and $\mu\left(\mathbf{w}_{i}\right)$ represents the additional deviation on plots owned by others as a function of $i$ 's own characteristics.

Suppose that for individuals belonging to the same nuclear family, we have $\delta_{j i}=\delta_{i j}=\delta_{n}>0$ and $\delta_{e}$ is the corresponding parameter for individuals belonging to different nuclear families such

\footnotetext{
${ }^{24}$ In game-theoretic terms, $\mu_{i j}$ depends on the equilibrium obtained in the subgame where household members make their labour allocations across plots.
} 
that $1>\delta_{n}>\delta_{e}>025$ Suppose that $i$ and $j$ share a nuclear family tie while $j^{\prime}$ is a cohabitating individual who belongs to a different nuclear family. If $i$ contributes positive amounts of labour on the plots of both $j$ and $j^{\prime}$, then, using (8) and (9), we obtain

$$
\begin{aligned}
\ln \left(\mu_{i i} \frac{L_{m i}}{A_{i}}\right)-\ln \left(\mu_{i j} \frac{L_{m j}}{A_{j}}\right)= & \frac{\rho}{\left[1-\rho\left(\beta_{1}+\beta_{2}\right)\right]} \ln \left[\frac{R_{i}\left(q_{i}, \mathbf{r}\right)}{R_{j}\left(q_{j}, \mathbf{r}\right)}\right]+\left[\frac{\rho\left(\alpha+\beta_{1}+\beta_{2}\right)-1}{1-\rho\left(\beta_{1}+\beta_{2}\right)}\right] \ln \left(\frac{A_{i}}{A_{j}}\right) \\
& -\left[\frac{1}{1-\rho\left(\beta_{1}+\beta_{2}\right)}\right] \ln \left(\delta_{n}\right)+\ln \mu\left(\mathbf{w}_{i}\right)+\ln \left[\frac{n_{m}(j)}{n_{m}(i)}\right] \\
\ln \left(\mu_{i i} \frac{L_{m i}}{A_{i}}\right)-\ln \left(\mu_{i j^{\prime}} \frac{L_{m j^{\prime}}}{A_{j^{\prime}}}\right)= & \frac{\rho}{\left[1-\rho\left(\beta_{1}+\beta_{2}\right)\right]} \ln \left[\frac{R_{i}\left(q_{i}, \mathbf{r}\right)}{R_{j^{\prime}}\left(q_{j^{\prime}}, \mathbf{r}\right)}\right]+\left[\frac{\rho\left(\alpha+\beta_{1}+\beta_{2}\right)-1}{1-\rho\left(\beta_{1}+\beta_{2}\right)}\right] \ln \left(\frac{A_{i}}{A_{j^{\prime}}}\right) \\
& -\left[\frac{1}{1-\rho\left(\beta_{1}+\beta_{2}\right)}\right] \ln \left(\delta_{e}\right)+\ln \mu\left(\mathbf{w}_{i}\right)+\ln \left[\frac{n_{m}\left(j^{\prime}\right)}{n_{m}(i)}\right]
\end{aligned}
$$

Following the same reasoning, we can derive parallel equations for individual female labour contributions across private plots. Equations (36) and (37) provide a link between $i$ 's (male) labour contribution on his private plot, the private plot of another household member, and the nature of the family tie between them. For example, if the private plots of $i$ and $j$ are identical (i.e. $\left.A_{i}=A_{j}\right)$, their preferences are perfectly aligned $\left(\delta_{n}=\delta_{j i}=\delta_{i j}=1\right)$ and equal numbers of men work on their respective plots $\left(n_{m}(i)=n_{m}(j)\right)$, then $i$ will work equal amounts of time on the two plots. If $\delta_{n}$ is below 1 , he will spend relatively more time on his own plot. More generally, the equations imply that, controlling for plot and individual characteristics and number of workers on the respective plots, $i$ contributes more labour per unit area on the private plot of a nuclear family member than that of an extended family member (or an unrelated individual living within the same household). We test this hypothesis using data on individual labour contributions on farm plots in Section 5.3 .

\section{References}

[1] Adepoju, A. (2005). African Families in the Twenty-First Century: Prospects and Challenges, iUniverse.

[2] Akresh, R. (2009). "Flexibility of household structure child fostering decisions in Burkina Faso", Journal of Human Resources, Vol. 44, No. 4, pp. 976-997.

[3] Akresh, R., J. Chen, C. Moore (2016). "Altruism, Cooperation, and Efficiency: Agricultural Production in Polygynous Households", Economic Development and Cultural Change, Vol. 64(4), pp. 661-696.

\footnotetext{
${ }^{25}$ The assumption that individuals sharing a nuclear family tie would exhibit higher levels of altruism towards each other than individuals sharing an extended family tie or no familial ties can be motivated by the evolutionary approach to familial ties and altruism, based on the work of Hamilton (1964), as discussed in Cox and Fafchamps (2008). In fact, this approach would yield more precise predictions regarding altruism between different households than what we are assuming here. Our simplified approach is due to the fact that the data provides limited information on the familial relations within the household.
} 
[4] Angelucci, M. and R. Garlick (2015). "Heterogeneity and Aggregation: Testing for Efficiency in Intra-Household Allocation." Department of Economics, Duke University.

[5] Ashraf, N. (2009). "Spousal Control and Intra-Household Decision Making: An Experimental Study in the Philippines", American Economic Review, Vol. 99(4), pp. 1245-1277.

[6] Attanasio, O. P. and V. Lechene (2014). "Efficient responses to targeted cash transfers." Journal of Political Economy, Vol. 122, No. 1, pp. 178-222.

[7] Baland, J-M., I. Bonjean, C. Guirkinger, R. Ziparo (2013). "The Economic Consequences of Mutual Help in Extended Families", University of Namur, mimeo.

[8] Bardhan, P. and C. Udry (1999). Development Economics. Oxford University Press.

[9] Becker, G. (1993). A Treatise on the Family, Harvard University Press.

[10] Berry, S. (1993). No Condition is Permanent: The Social Dynamics of Agrarian Change in Sub-Saharan Africa. University of Wisconsin Press.

[11] Bobonis, G. J. (2009). "Is the allocation of resources within the household efficient? New evidence from a randomized experiment." Journal of Political Economy, Vol. 117, No. 3, pp. 453-503.

[12] Browning, M., F. Bourguignon, P. A. Chiappori and V. Lechene. (1994). "Income and outcomes: A structural model of intrahousehold allocation." Journal of Political Economy, Vol.102, No.6, pp. 1067-1096.

[13] Browning, M. and P. A. Chiappori (1998). "Efficient intra-household allocations: A general characterization and empirical tests." Econometrica (1998), Vol. 66, No. 6, pp. 1241-1278

[14] Chiappori, P. A. (1988). "Rational household labor supply." Econometrica, Vol. 56, No. 1, pp. 63-90

[15] Chiappori, P. A. (1992). "Collective labor supply and welfare." Journal of political Economy, Vol. 100, No. 3, pp.437-467.

[16] Chiappori, P. A., B. Fortin and G. Lacroix (2002). "Marriage market, divorce legislation, and household labor supply." Journal of Political Economy, Vol. 110, No. 1, pp. 37-72.

[17] Coulson, E. (1962). "Family change in contemporary Africa", Annals of the New York Academy of Sciences, Vol. 96, No. 2, pp. 641-652.

[18] Cox, D. and M. Fafchamps (2008). "Extended family and kinship networks: economic insights and evolutionary directions, in: T.P. Schultz and J. Strauss (eds) Handbook of Development Economics, Vol. 4, Amsterdam: Elsevier, pp. 3711-3784. 
[19] Dercon, S. and P. Krishnan (2000). "In sickness and in health: Risk sharing within households in rural Ethiopia." Journal of political Economy, Vol. 108, No. 4, pp.688-727.

[20] Di Falco and Bulte (2011). "A Dark Side of Social Capital? Kinship Consumption and Savings", Journal of Development Studies, vol. 47(8)

[21] Di Falco and Bulte (2013). "The Impact of Kinship Network on the Adoption of RiskMitigating Strategies in Ethiopia", World Development, Vol. 43

[22] Duflo, E. and C. Udry. (2004). "Intrahousehold Resource Allocation in Cote d'Ivoire: Social Norms, Separate Accounts and Consumption Choices". Mimeo, Yale University, December 2004 .

[23] Doss, C. (2013). "Intrahousehold bargaining and resource allocation in developing countries", The World Bank Research Observer, Vol. 28(1), pp. 52-78.

[24] Emergency Nutrition Network (2012) Mid Upper Arm Circumference and Weightfor-Height Z-score as Indicators of Severe Acute Malnutrition: a Consultation of Operational Agencies and Academic Specialists to Understand the Evidence, Identify Knowledge Gaps and to Inform Operational Guidance, London, UK, http://www.cmamforum.org/Pool/Resources/MUACWFH-Report-ENN-2013.pdf

[25] Fafchamps, M., C. Udry, C. and K. Czukas (1998). "Drought and saving in West Africa: are livestock a buffer stock?", Journal of Development Economics, Vol. 55, No. 2, pp. 273-305

[26] Foster, A. D., \& Rosenzweig, M. R. (2002). "Household Division and Rural Economic Growth". Review of Economic Studies, Vol. 69(4), pp. 839-869.

[27] Goldstein, M., and C. Udry, (2008). "The profits of power: Land rights and agricultural investment in Ghana". Journal of Political Economy, Vol. 116, No. 6, pp. 981-1022.

[28] Goossens S., Y. Bekele, O. Yun, G. Harczi, M. Ouannes, S. Shepherd (2012). "Mid-Upper Arm Circumference Based Nutrition Programming: Evidence for a New Approach in Regions with High Burden of Acute Malnutrition." PLoS ONE Vol. 7(11)

[29] Guirkinger, C. and J-P Platteau (2014). "The Effect of Land Scarcity on Farm Structure: Empirical Evidence from Mali". Economic Development and Cultural Change, Vol. 62, No. 2, pp. 195-238.

[30] Guirkinger, C. and J-P. Platteau (2015). "Transformation of the Family Farm under Rising Land Pressure: A Theoretical Essay", Journal of Comparative Economics.

[31] Guirkinger, C., J-P. Platteau and T. Goetghebuer (2015). "Productive Inefficiency in Extended Agricultural Households: Evidence from Mali", Journal of Development Economics, Vol. 116, pp. 17-27. 
[32] Haddad, L., J. Hoddinott, and H. Alderman (1997). Intrahousehold Resource Allocation in Developing Countries: Models, Methods, and Policy. Johns Hopkins University Press.

[33] Hamilton, W.D. (1964). "The genetical evolution of social behavior, I and II", Journal of Theoretical Biology, Vol. 7, pp. 1-52.

[34] Kazianga, H., and C. Udry (2006) "Consumption smoothing? Livestock, insurance and drought in rural Burkina Faso". Journal of Development Economics, Vol. 79 No. 2, pp.413-446.

[35] Kazianga, H. and Z. Wahhaj (2013) "Gender, Social Norms, and Household Production in Burkina Faso", Economic Development and Cultural Change, Vol. 61, No. 3, pp. 539-576.

[36] Kazianga, H. and Z. Wahhaj (2016). "Intra-household Resource Allocation and Familial Ties", Oxford CSAE Working Paper WPS 2016-06.

[37] Kimhi, A. (2004). "Family Composition and Off-Farm Participation Decisions in Israeli Farm Households", American Journal of Agricultural Economics, Vol. 86(2), pp. 502-512.

[38] Ligon, E., J. P. Thomas and T. Worrall (2002). "Informal Insurance Arrangements with Limited Commitment: Theory and Evidence from Village Economies", Review of Economic Studies, Vol. 69(1), pp. 209-244.

[39] Ligon, E. (2002). "Dynamic bargaining in households (with an application to Bangladesh)", Giannini Foundation Working Paper.

[40] Lundberg, S. (1988). "Labor supply of husbands and wives: A simultaneous equations approach." The Review of Economics and Statistics, Vol. 70, No.2, pp. 224-235.

[41] Mazzocco, M. (2007). "Household intertemporal behaviour: A collective characterization and a test of commitment." The Review of Economic Studies, Vol. 74(3), pp. 857-895.

[42] Rangel, M. A. and D. Thomas, D. (2005). "Out of West Africa: Evidence on the efficient allocation of resources within farm households." Harris School of Public Policy, University of Chicago.

[43] Ravallion, M., and S. Chaudhuri, S. (1997) "Risk and insurance in village India: Comment". Econometrica, pp. 171-184.

[44] Paxson, C. H. (1992). "Using weather variability to estimate the response of savings to transitory income in Thailand", The American Economic Review, Vol.82, No.1 pp. 15-33.

[45] Rosenzweig, M. (1988). "Risk, Implicit Contracts and the Family in Rural Areas of Low-Income Countries", Economic Journal, Vol. 98(393), pp. 1148-1170. 
[46] Rosenzweig, M. and K. Wolpin (1985) "Specific Experience, Household Structure and Intergenerational Transfers: Farm Family Land and Labor Arrangements in Developing Countries", Quarterly Journal of Economics, Vol. 100, Supplement.

[47] Thomas, D. (1990). "Intra-household resource allocation: An inferential approach." Journal of Human Resources, Vol. 25(4), pp. 635-664.

[48] Townsend, R. M. (1994) "Risk and insurance in village India". Econometrica, pp. 539-591.

[49] Udry, C. (1996). "Gender, agricultural production, and the theory of the household". Journal of Political Economy,Vol. 104, No. 5, pp. 1010-1046.

[50] Von Braun, J. and P.J.R. Webb (1989). "The Impact of New Crop Technology on the Agricultural Division of Labor in a West African Setting", Economic Development and Cultural Change, Vol. 37(3), pp. 513-534.

[51] Young, L. and N. Ansell. (2003). "Fluid Households, Complex Families: The Impacts of Children's Migration as a Response to HIV/AIDS in Southern Africa". The Professional Geographer, Vol. 55, No. 4, pp. 464-476. 


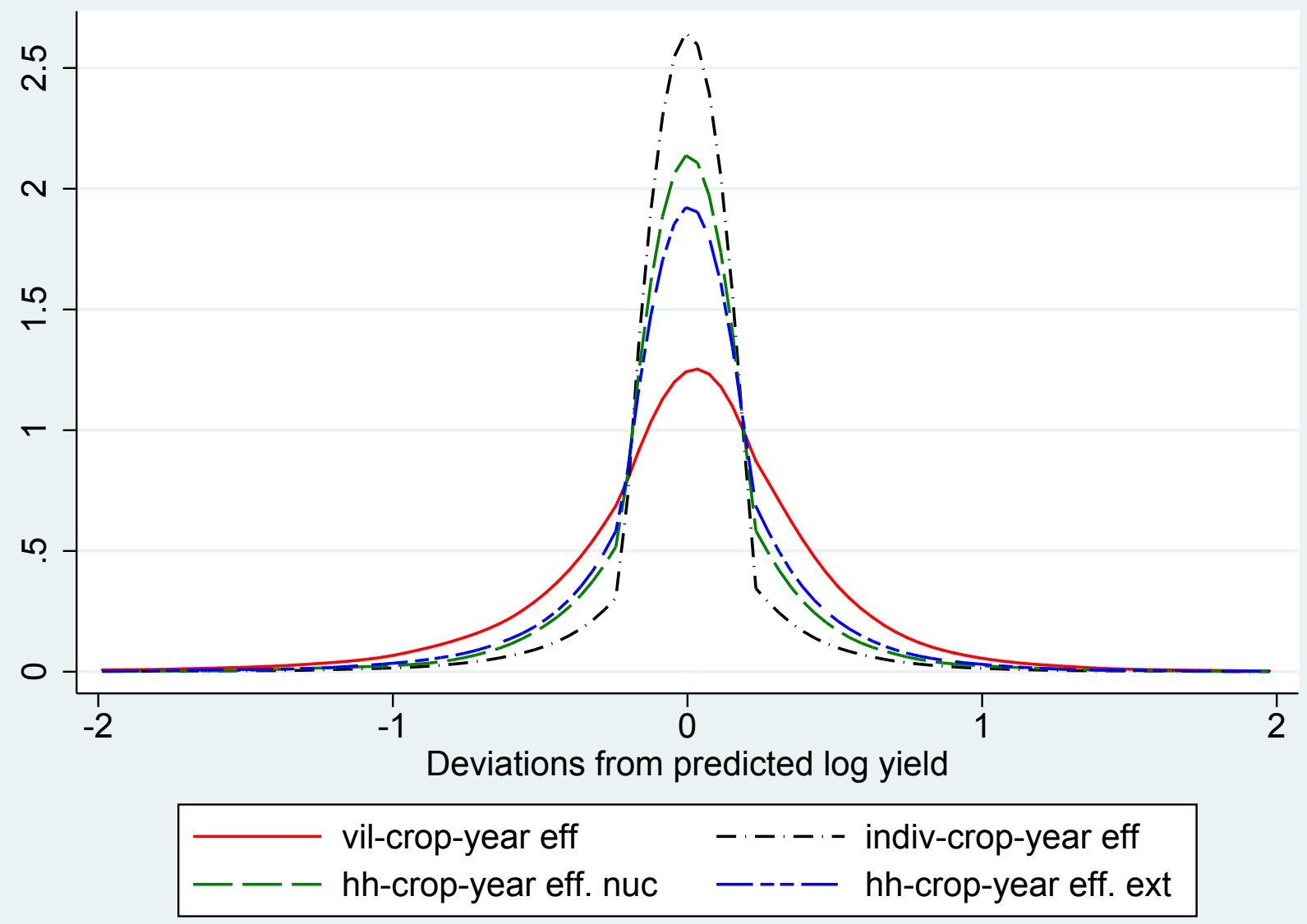

Figure 1: Plot yield dispersions 
Tables 
Table 1: Household Composition and Plot Characteristics of Extended and Nuclear Family Households

\begin{tabular}{|c|c|c|c|c|c|c|}
\hline & \multicolumn{2}{|c|}{$\begin{array}{l}\text { Extended Family } \\
\text { Households }\end{array}$} & \multicolumn{2}{|c|}{$\begin{array}{l}\text { Nuclear Family } \\
\text { Households }\end{array}$} & \multirow[t]{2}{*}{ Difference } & \multirow[t]{2}{*}{ t-stat } \\
\hline & mean & (sd) & mean & (sd) & & \\
\hline \multicolumn{7}{|l|}{ Household Head's Characteristics } \\
\hline Gender $(1=$ Male, $0=$ Female $)$ & 0.95 & $(0.22)$ & 0.94 & $(0.24)$ & 0.01 & 2.03 \\
\hline Age & 50.75 & $(15.88)$ & 48.79 & $(13.43)$ & 1.96 & 7.84 \\
\hline Married? $(1=$ Yes, $0=$ No $)$ & 0.92 & $(0.27)$ & 0.93 & $(0.26)$ & -0.01 & -1.88 \\
\hline \# of Wives & 1.57 & $(1.13)$ & 1.47 & $(0.98)$ & 0.10 & 5.56 \\
\hline Literate? $(1=$ Yes, $0=$ No $)$ & 0.26 & $(0.44)$ & 0.23 & $(0.42)$ & 0.02 & 2.93 \\
\hline Household Size & 11.78 & (6.70) & 7.30 & (3.86) & 4.48 & 49.60 \\
\hline \# Married Men & 1.76 & $(1.12)$ & 1.04 & $(0.48)$ & 0.72 & 51.79 \\
\hline \# Extended Family Members & 4.59 & $(5.00)$ & - & - & 4.59 & 82.56 \\
\hline \# Observations & 8080 & & 5723 & & & \\
\hline \multicolumn{7}{|l|}{ Household Plot Characteristics } \\
\hline Total Plot Area (hectares) & 7.14 & (7.48) & 4.50 & $(4.48)$ & 2.65 & 25.90 \\
\hline Proportion of Collective Plot & 0.74 & $(0.30)$ & 0.75 & $(0.33)$ & 0.00 & -0.55 \\
\hline \# of Plots & 7.54 & $(5.00)$ & 5.64 & $(3.55)$ & 1.90 & 26.11 \\
\hline \# of Collective Plots & 4.29 & $(2.95)$ & 3.52 & $(2.49)$ & 0.76 & 16.39 \\
\hline \# of Private Plots & 3.17 & (3.76) & 2.06 & $(2.45)$ & 1.11 & 21.07 \\
\hline \# of Male Private Plots & 2.39 & (3.14) & 1.62 & $(2.13)$ & 0.77 & 17.17 \\
\hline \# Observations & 7516 & & 5220 & & & \\
\hline
\end{tabular}

Source: Authors calculations using data from the Ministry of Agriculture of Burkina Faso.

Notes: Nuclear family households are defined as households consisting of the head, his spouse or spouses, and their children. Households with one or more individuals who do not belong to the head's nuclear family are classified as extended family households. Total area is the sum of the area of all plots farmed by the household in a given year. Collective plots refer to plots managed by the household head (or, occasionally, by another household member), the proceeds of which are shared among all household members. Private plots refer to plot managed by individual household members who then make decisions on how to allocate the proceeds. 
Table 2: Labour, Land Allocation, and Farm Productivity within Extended and Nuclear Family Households

\begin{tabular}{|c|c|c|c|c|c|c|}
\hline & \multicolumn{2}{|c|}{ Private plots } & \multicolumn{2}{|c|}{ Collective plots managed by: } & \multicolumn{2}{|c|}{$\begin{array}{l}\text { Share allocated to } \\
\text { Collective Plots: }\end{array}$} \\
\hline & Men & Women & $\begin{array}{c}\text { Household } \\
\text { Head }\end{array}$ & $\begin{array}{c}\text { Other Family } \\
\text { Members }\end{array}$ & $\begin{array}{c}\text { Managed by } \\
\text { Household } \\
\text { Head }\end{array}$ & All \\
\hline \multicolumn{7}{|l|}{ All households } \\
\hline Male Labour (days) & 20.39 & 16.39 & 169.65 & 6.10 & 0.80 & 0.83 \\
\hline Female Labour (days) & 11.39 & 55.29 & 137.24 & 6.18 & 0.65 & 0.68 \\
\hline Total Labour (days) & 31.96 & 71.95 & 307.44 & 12.34 & 0.73 & 0.75 \\
\hline Area (ha) & 0.50 & 0.87 & 4.21 & 0.16 & 0.73 & 0.76 \\
\hline Farming intensity (days/ha) & 64.15 & 82.96 & 72.99 & 76.66 & & \\
\hline Yield (CFA/ha) & 88674.89 & 79641.86 & 89073.29 & 86037.14 & & \\
\hline \multicolumn{7}{|l|}{ Nuclear households } \\
\hline Male Labour (days) & 13.90 & 13.70 & 139.05 & 2.46 & 0.82 & 0.84 \\
\hline Female Labour (days) & 7.28 & 44.07 & 112.41 & 3.09 & 0.67 & 0.69 \\
\hline Total Labour (days) & 21.22 & 57.86 & 251.92 & 5.64 & 0.75 & 0.77 \\
\hline Area (ha) & 0.32 & 0.64 & 3.31 & 0.07 & 0.76 & 0.78 \\
\hline Farming intensity (days/ha) & 66.93 & 90.53 & 76.15 & 84.00 & & \\
\hline Yield (CFA/ha) & 95487.73 & 85059.06 & 88304.52 & 81561.08 & & \\
\hline Shadow Price of Land & 446.30 & 180.73 & & & & \\
\hline \multicolumn{7}{|l|}{ Extended households } \\
\hline Male Labour (days) & 24.89 & 18.25 & 190.90 & 8.63 & 0.79 & 0.82 \\
\hline Female Labour (days) & 14.24 & 63.09 & 154.48 & 8.33 & 0.64 & 0.68 \\
\hline Total Labour (days) & 39.43 & 81.74 & 346.00 & 17.00 & 0.71 & 0.75 \\
\hline Area (ha) & 0.62 & 1.03 & 4.84 & 0.23 & 0.72 & 0.75 \\
\hline Farming intensity (days/ha) & 63.17 & 79.69 & 71.49 & 75.15 & & \\
\hline Yield (CFA/ha) & 86270.92 & 77297.68 & 89438.24 & 86959.95 & & \\
\hline Shadow Price of Land & 319.70 & 158.71 & & & & \\
\hline
\end{tabular}

Source: Authors' calculations using data from the Ministry of Agriculture of Burkina Faso.

Notes: Nuclear family households are defined as households consisting of the head, his spouse or spouses, and their children. Households with one or more individuals who do not belong to the head's nuclear family are classified as extended family households. Total area is the sum of the area of all plots farmed by the household in a given year. Collective plots refer to plots managed by the household head (or, occasionally, by another household member), the proceeds of which are shared among all household members. Private plots refer to plot managed by individual household members who then make decisions on how to allocate the proceeds. Yield is measured as the value of harvest divided by the size of the plot. The shadow price of land is measured as total labour allocated to collective plots (in "person-days") divided by the size of private plots in hectares. 
Table 3: Estimates of Plot Yields for Extended and Nuclear Family Households

\begin{tabular}{|c|c|c|c|}
\hline \multirow[b]{2}{*}{ VARIABLES } & \multicolumn{3}{|c|}{ Dep. Var.: In(Plot Yield in Value/Hectare) } \\
\hline & $\begin{array}{c}\text { All } H^{\prime} \text { holds } \\
\text { (1) }\end{array}$ & $\begin{array}{c}\text { Extended } \\
\text { (2) }\end{array}$ & $\begin{array}{c}\text { Nuclear } \\
\text { (3) }\end{array}$ \\
\hline \multicolumn{4}{|l|}{ Plot Type: ('collective plots' excluded) } \\
\hline Male Private Plot & $\begin{array}{c}-0.24 * * * \\
(0.02)\end{array}$ & $\begin{array}{c}-0.27^{* * *} \\
(0.03)\end{array}$ & $\begin{array}{c}-0.14 * * * \\
(0.05)\end{array}$ \\
\hline Female Private Plot & $\begin{array}{c}-0.48^{* * *} \\
(0.02)\end{array}$ & $\begin{array}{c}-0.54 * * * \\
(0.02)\end{array}$ & $\begin{array}{c}-0.33^{* * *} \\
(0.03)\end{array}$ \\
\hline \multicolumn{4}{|l|}{ Topography: ('flat ground' excluded) } \\
\hline Low Ground & $\begin{array}{l}-0.03 \\
(0.02)\end{array}$ & $\begin{array}{l}-0.03 \\
(0.03)\end{array}$ & $\begin{array}{l}-0.01 \\
(0.05)\end{array}$ \\
\hline Sloping Ground & $\begin{array}{c}0.01 \\
(0.03)\end{array}$ & $\begin{array}{l}-0.01 \\
(0.04)\end{array}$ & $\begin{array}{c}0.04 \\
(0.06)\end{array}$ \\
\hline \multicolumn{4}{|l|}{ Plot Location: ('cases' excluded) } \\
\hline Brousse & $\begin{array}{c}0.16^{* * *} \\
(0.02)\end{array}$ & $\begin{array}{c}0.16 * * * \\
(0.02)\end{array}$ & $\begin{array}{c}0.16^{* * *} \\
(0.03)\end{array}$ \\
\hline Campement & $\begin{array}{c}0.19 * * * \\
(0.05)\end{array}$ & $\begin{array}{c}0.22 * * * \\
(0.06)\end{array}$ & $\begin{array}{c}0.11 \\
(0.10)\end{array}$ \\
\hline Plot Owner Age & $\begin{array}{c}0.02 * * * \\
(0.00)\end{array}$ & $\begin{array}{c}0.02 * * * \\
(0.00)\end{array}$ & $\begin{array}{c}0.03 * * * \\
(0.00)\end{array}$ \\
\hline Age Squared & $\begin{array}{c}-0.02 * * * \\
(0.00)\end{array}$ & $\begin{array}{c}-0.01 * * * \\
(0.00)\end{array}$ & $\begin{array}{c}-0.02 * * * \\
(0.00)\end{array}$ \\
\hline Constant & $\begin{array}{c}12.42^{* * *} \\
(0.06)\end{array}$ & $\begin{array}{c}12.52 * * * \\
(0.07)\end{array}$ & $\begin{array}{c}12.05^{* * *} \\
(0.11)\end{array}$ \\
\hline Observations & 81,485 & 53,366 & 28,119 \\
\hline R-squared & 0.37 & 0.37 & 0.37 \\
\hline \# H'hold-Crop-Year Groups & 49,750 & 30,813 & 18,937 \\
\hline F-Stat. test: Male Plot $=$ Female Plot $=0$ & 256.9 & 244.8 & 53.25 \\
\hline $\mathrm{p}$ value & 0.00 & 0.00 & 0.00 \\
\hline
\end{tabular}

Source: Authors calculations using data from the Ministry of Agriculture of Burkina Faso.

Notes: ${ }^{* * *}$ significant at the 1 percent level, ${ }^{* *}$ significant at the 5 percent level and ${ }^{*}$ significant at the 10 percent level. Robust standard errors, clustered at the village level. The dependent variable is natural log of plot yield measured in the local currency per hectare. The regressions control for household-crop-year fixed effects. Dummy variables representing the plot manager education level and dummy variables representing plot size by deciles are included in the regressions but not shown. 
Table 4: Estimates of Plot Yields for Different Plot Ownership Categories within Extended and Nuclear Family Households.

\begin{tabular}{|c|c|c|c|}
\hline \multirow[b]{2}{*}{ VARIABLES } & \multicolumn{3}{|c|}{ Dep. Variable: In(Plot Yield in Value/Hectare) } \\
\hline & $\begin{array}{c}\text { All } H^{\prime} \text { holds } \\
\text { (1) }\end{array}$ & $\begin{array}{c}\text { Extended } \\
\text { (2) }\end{array}$ & $\begin{array}{c}\text { Nuclear } \\
\text { (3) }\end{array}$ \\
\hline \multicolumn{4}{|c|}{ Plot Type: (head's 'collective plots' excluded) } \\
\hline Other Collective Plots & $\begin{array}{c}-0.27^{* * *} \\
(0.04)\end{array}$ & $\begin{array}{c}-0.25 * * * \\
(0.04)\end{array}$ & $\begin{array}{c}-0.41^{* * *} \\
(0.08)\end{array}$ \\
\hline Head's Private Plots & $\begin{array}{c}-0.18^{* * *} \\
(0.04)\end{array}$ & $\begin{array}{c}-0.21^{* * *} \\
(0.04)\end{array}$ & $\begin{array}{l}-0.10 \\
(0.06)\end{array}$ \\
\hline Spouse's Private Plots & $\begin{array}{c}-0.52 * * * \\
(0.02)\end{array}$ & $\begin{array}{c}-0.58 * * * \\
(0.03)\end{array}$ & $\begin{array}{c}-0.39 * * * \\
(0.04)\end{array}$ \\
\hline Son's Private Plots & $\begin{array}{c}-0.36^{* * *} \\
(0.03)\end{array}$ & $\begin{array}{c}-0.36^{* * *} \\
(0.03)\end{array}$ & $\begin{array}{c}-0.32 * * * \\
(0.07)\end{array}$ \\
\hline Daughter's Private Plots & $\begin{array}{c}-0.56^{* * *} \\
(0.05)\end{array}$ & $\begin{array}{c}-0.59 * * * \\
(0.07)\end{array}$ & $\begin{array}{c}-0.47^{* * *} \\
(0.08)\end{array}$ \\
\hline Other Male Relatives & $\begin{array}{c}-0.33^{* * *} \\
(0.04)\end{array}$ & $\begin{array}{c}-0.35^{* * *} \\
(0.04)\end{array}$ & \\
\hline Other Female Relatives & $\begin{array}{c}-0.50 * * * \\
(0.03)\end{array}$ & $\begin{array}{c}-0.53^{* * *} \\
(0.03)\end{array}$ & \\
\hline Unrelated Males & $\begin{array}{c}-0.38 * * * \\
(0.14)\end{array}$ & $\begin{array}{c}-0.42 * * * \\
(0.14)\end{array}$ & \\
\hline Unrelated Females & $\begin{array}{c}-0.55^{* * *} \\
(0.03)\end{array}$ & $\begin{array}{c}-0.59 * * * \\
(0.03)\end{array}$ & \\
\hline Observations & 81,485 & 53,366 & 28,119 \\
\hline R-squared & 0.37 & 0.37 & 0.38 \\
\hline \# H’hold-Crop-Year Groups & 49,750 & 30,813 & 18,937 \\
\hline F-Stat. test: son $=$ other male & 0.29 & 0.15 & \\
\hline $\mathrm{p}$ value & 0.75 & 0.86 & \\
\hline F-Stat. test: daughter $=$ other female & 1.42 & 1.54 & \\
\hline $\mathrm{p}$ value & 0.24 & 0.22 & \\
\hline $\begin{array}{l}\text { F-Stat. test: all nuclear private } \& \text { othe } \\
\text { collective equal }\end{array}$ & 23.95 & 30.33 & 1.71 \\
\hline $\mathrm{p}$ value & 0.00 & 0.00 & 0.16 \\
\hline F-Stat. test: all other plots equal & 13.74 & 16.60 & \\
\hline $\mathrm{p}$ value & 0.00 & 0.00 & \\
\hline
\end{tabular}

Source: Authors calculations using data from the Ministry of Agriculture of Burkina Faso.

Notes: ${ }^{* * *}$ significant at the 1 percent level, ${ }^{* *}$ significant at the 5 percent level and ${ }^{*}$ significant at the 10 percent level. Robust standard errors, clustered at the village level. The dependent variables are the natural log of plot yield measured in the local currency per hectare. The regressions include household-crop-year fixed effects, the plot manager's education level and age, categorical variables representing plot size by deciles and plot characteristics and a constant term (not shown). 
Table 5: Labour Use Intensity across Plot Ownership Categories within Nuclear and Extended Family Households

\begin{tabular}{|c|c|c|c|c|c|c|c|c|}
\hline \multirow{2}{*}{$\begin{array}{l}\text { Dep. Variable: } \\
\text { In(labour/hecture) from ... }\end{array}$} & \multicolumn{4}{|c|}{ Nuclear households } & \multicolumn{4}{|c|}{ Extended households } \\
\hline & $\begin{array}{c}\text { Men } \\
(1) \\
\end{array}$ & $\begin{array}{c}\text { Women } \\
\text { (2) }\end{array}$ & $\begin{array}{c}\text { Children } \\
\text { (3) }\end{array}$ & $\begin{array}{l}\text { All h'hold } \\
\text { (4) }\end{array}$ & $\begin{array}{l}\text { Men } \\
(5)\end{array}$ & $\begin{array}{l}\text { Women } \\
(6)\end{array}$ & $\begin{array}{c}\text { Children } \\
\text { (7) }\end{array}$ & $\begin{array}{c}\text { All h'hold } \\
\text { (8) }\end{array}$ \\
\hline \multicolumn{9}{|c|}{ Plot Type: (head's 'collective plots' excluded) } \\
\hline Other Collecive Plots & $\begin{array}{c}-1.11^{* * *} \\
(0.19)\end{array}$ & $\begin{array}{c}-0.12 \\
(0.19)\end{array}$ & $\begin{array}{l}-0.00 \\
(0.00)\end{array}$ & $\begin{array}{c}-0.43 * * * \\
(0.07)\end{array}$ & $\begin{array}{c}-0.87^{* * *} \\
(0.12)\end{array}$ & $\begin{array}{c}-0.15^{*} \\
(0.09)\end{array}$ & $\begin{array}{l}-0.01 \\
(0.01)\end{array}$ & $\begin{array}{c}-0.34^{* * *} \\
(0.04)\end{array}$ \\
\hline Head's Private Plots & $\begin{array}{c}-0.09 \\
(0.13)\end{array}$ & $\begin{array}{c}-0.93 * * * \\
(0.14)\end{array}$ & $\begin{array}{c}0.01 \\
(0.00)\end{array}$ & $\begin{array}{c}-0.27^{* * *} \\
(0.05)\end{array}$ & $\begin{array}{c}-0.43 * * * \\
(0.09)\end{array}$ & $\begin{array}{c}-0.73 * * * \\
(0.08)\end{array}$ & $\begin{array}{c}0.00 \\
(0.00)\end{array}$ & $\begin{array}{c}-0.44^{* * *} \\
(0.04)\end{array}$ \\
\hline Spouse's Private Plots & $\begin{array}{c}-1.99 * * * \\
(0.10)\end{array}$ & $\begin{array}{c}0.15^{* *} \\
(0.07)\end{array}$ & $\begin{array}{l}-0.00 * \\
(0.00)\end{array}$ & $\begin{array}{c}-0.53 * * * \\
(0.03)\end{array}$ & $\begin{array}{c}-2.22 * * * \\
(0.07)\end{array}$ & $\begin{array}{c}0.03 \\
(0.06)\end{array}$ & $\begin{array}{l}-0.00 \\
(0.00)\end{array}$ & $\begin{array}{c}-0.71 * * * \\
(0.02)\end{array}$ \\
\hline Son's Private Plots & $\begin{array}{c}0.65^{* * *} \\
(0.19)\end{array}$ & $\begin{array}{c}-2.20 * * * \\
(0.19)\end{array}$ & $\begin{array}{c}0.00 \\
(0.00)\end{array}$ & $\begin{array}{c}-0.50 * * * \\
(0.06)\end{array}$ & $\begin{array}{c}-0.26 * * * \\
(0.08)\end{array}$ & $\begin{array}{c}-1.32 * * * \\
(0.10)\end{array}$ & $\begin{array}{l}-0.00 \\
(0.00)\end{array}$ & $\begin{array}{c}-0.57 * * * \\
(0.03)\end{array}$ \\
\hline Daughter's Private Plots & $\begin{array}{c}-1.50 * * * \\
(0.24)\end{array}$ & $\begin{array}{c}0.05 \\
(0.15)\end{array}$ & $\begin{array}{l}-0.00 \\
(0.00)\end{array}$ & $\begin{array}{c}-0.43^{* * *} \\
(0.08)\end{array}$ & $\begin{array}{c}-2.20 * * * \\
(0.15)\end{array}$ & $\begin{array}{c}0.12 \\
(0.10)\end{array}$ & $\begin{array}{l}-0.00 \\
(0.00)\end{array}$ & $\begin{array}{c}-0.65 * * * \\
(0.05)\end{array}$ \\
\hline Other Male Relatives & & & & & $\begin{array}{c}-0.40 * * * \\
(0.08)\end{array}$ & $\begin{array}{c}-1.34 * * * \\
(0.11)\end{array}$ & $\begin{array}{l}-0.01 * \\
(0.01)\end{array}$ & $\begin{array}{c}-0.58^{* * *} \\
(0.04)\end{array}$ \\
\hline Other Female Relatives & & & & & $\begin{array}{c}-2.33 * * * \\
(0.10)\end{array}$ & $\begin{array}{c}0.16^{* *} \\
(0.08)\end{array}$ & $\begin{array}{l}-0.00 \\
(0.00)\end{array}$ & $\begin{array}{c}-0.68 * * * \\
(0.03)\end{array}$ \\
\hline Unrelated Males & & & & & $\begin{array}{c}-0.62^{*} \\
(0.33)\end{array}$ & $\begin{array}{c}-1.59 * * * \\
(0.48)\end{array}$ & $\begin{array}{l}-0.04 \\
(0.04)\end{array}$ & $\begin{array}{c}-0.74^{* * *} \\
(0.09)\end{array}$ \\
\hline Unrelated Female & & & & & $\begin{array}{c}-2.22 * * * \\
(0.11)\end{array}$ & $\begin{array}{c}0.01 \\
(0.07)\end{array}$ & $\begin{array}{c}0.00 \\
(0.00)\end{array}$ & $\begin{array}{c}-0.72 * * * \\
(0.03)\end{array}$ \\
\hline Observations & 28,119 & 28,119 & 28,119 & 28,119 & 53,366 & 53,366 & 53,366 & 53,366 \\
\hline R-squared & 0.41 & 0.44 & 0.01 & 0.76 & 0.36 & 0.41 & 0.01 & 0.74 \\
\hline F-Stat. test-1 & 98.99 & 71.79 & 0.94 & 1.45 & 140.10 & 60.98 & 1.20 & 27.13 \\
\hline $\mathrm{p}$ value & 0.00 & 0.00 & 0.42 & 0.23 & 0.19 & 0.00 & 0.31 & 0.00 \\
\hline \multicolumn{2}{|l|}{ F-Stat. test son $=$ other male } & & & & 1.65 & 0.16 & 1.07 & 1.92 \\
\hline \multicolumn{2}{|l|}{$\mathrm{p}$ value } & & & & 0.53 & 0.86 & 0.40 & 0.15 \\
\hline \multirow{2}{*}{\multicolumn{2}{|c|}{$\begin{array}{l}\text { F-Stat. test daughter }=\text { other female } \\
p \text { value }\end{array}$}} & & & & 0.63 & 3.88 & 0.98 & 1.71 \\
\hline & & & & & 0.00 & 0.00 & 0.38 & 0.00 \\
\hline \multicolumn{2}{|c|}{ F-Stat. test all other plots equal } & & & & 77.74 & 37.31 & 1.05 & 13.57 \\
\hline$p$ value & & & & & 0.00 & 0.02 & 0.34 & 0.18 \\
\hline
\end{tabular}

Source: Authors' calculations using data from the Ministry of Agriculture of Burkina Faso.

Notes: ${ }^{* * *}$ significant at the 1 percent level, ${ }^{* *}$ significant at the 5 percent level and ${ }^{*}$ significant at the 10 percent level. Robust standard errors, clustered at the village level. The dependent variables are the natural log of male, female, child and total household labour. All regressions include household-crop-year fixed effects, and controls for household demographic composition, age of the household head, plot characteristics and a constant term (not shown). F-Stat. test-1 is short for an F-test that the coefficients for nuclear family private plots and other collective plots are all equal. 


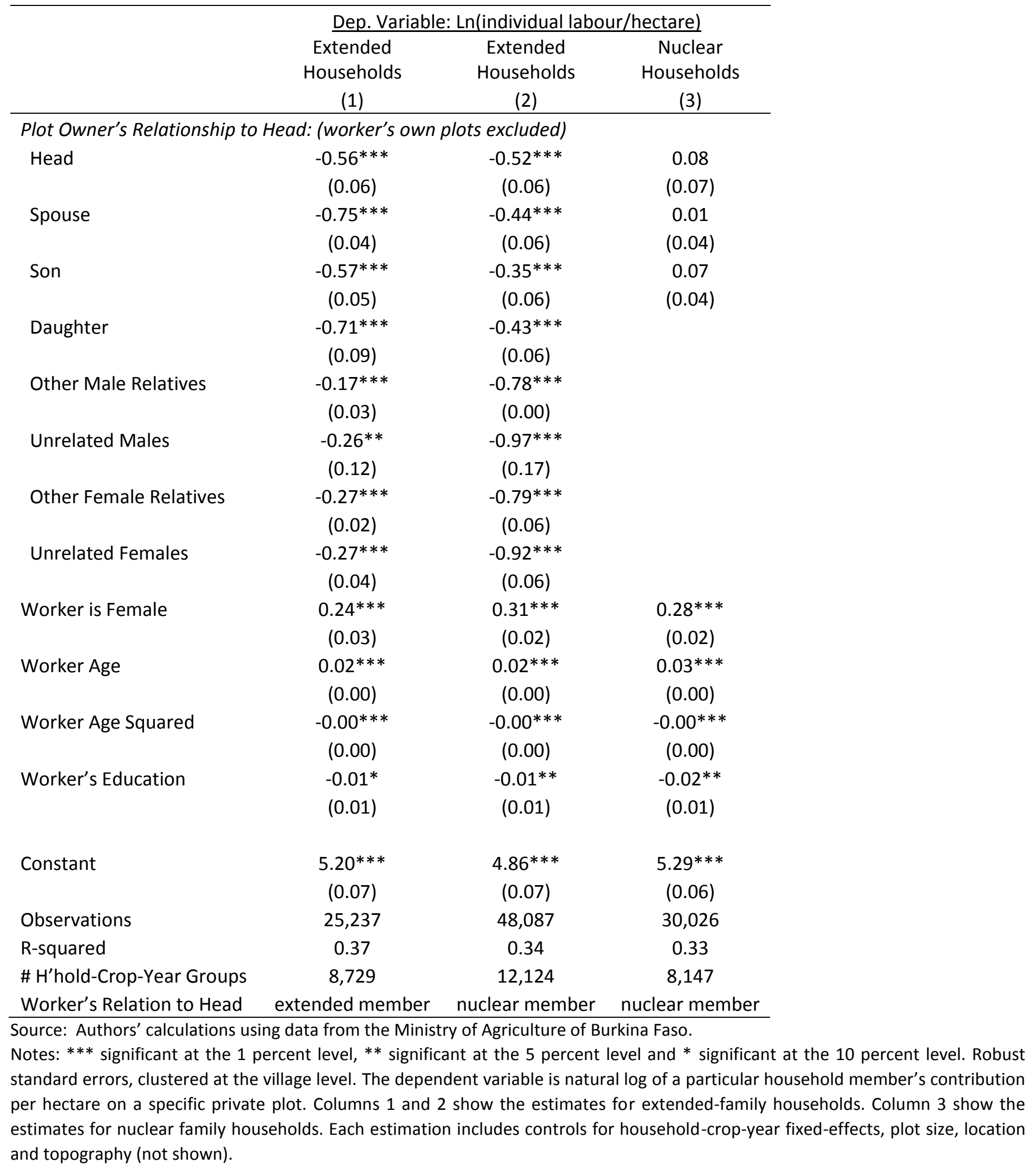




\begin{tabular}{|c|c|c|c|c|c|c|}
\hline & \multicolumn{6}{|c|}{ Dependent Variable: Ln(Labour/Hectare) } \\
\hline & $\begin{array}{c}\text { All H'holds } \\
\text { (1) }\end{array}$ & $\begin{array}{c}\text { Extended } \\
(2)\end{array}$ & $\begin{array}{c}\text { Nuclear } \\
(3)\end{array}$ & $\begin{array}{c}\text { All H'holds } \\
(4)\end{array}$ & $\begin{array}{c}\text { Extended } \\
(5) \\
\end{array}$ & $\begin{array}{l}\text { Nuclear } \\
(6)\end{array}$ \\
\hline \multicolumn{7}{|c|}{ Worker's Relationship to Head (head is excluded) } \\
\hline \multirow[t]{2}{*}{ Spouse } & $-0.81 * * *$ & $-0.88 * * *$ & $-0.56 * * *$ & $-0.92 * * *$ & $-0.94 * * *$ & $-0.66 * * *$ \\
\hline & $(0.08)$ & $(0.09)$ & $(0.11)$ & $(0.08)$ & $(0.09)$ & $(0.10)$ \\
\hline \multirow[t]{2}{*}{ Son } & $-0.42 * * *$ & $-0.45 * * *$ & -0.07 & $-0.47 * * *$ & $-0.47 * * *$ & -0.08 \\
\hline & $(0.09)$ & $(0.10)$ & $(0.18)$ & $(0.08)$ & $(0.10)$ & $(0.15)$ \\
\hline \multirow[t]{2}{*}{ Daughter } & $-1.61 * * *$ & $-1.76 * * *$ & $-0.98 * * *$ & $-1.62 * * *$ & $-1.78 * * *$ & $-0.96 * * *$ \\
\hline & $(0.12)$ & $(0.13)$ & $(0.21)$ & $(0.11)$ & $(0.13)$ & $(0.19)$ \\
\hline \multirow[t]{2}{*}{ Other Male Relatives } & $-0.54 * * *$ & $-0.61 * * *$ & & $-0.57 * * *$ & $-0.61 * * *$ & \\
\hline & $(0.10)$ & $(0.10)$ & & $(0.10)$ & $(0.10)$ & \\
\hline \multirow[t]{2}{*}{ Other Female Relatives } & $-2.20 * * *$ & $-2.24 * * *$ & & $-2.30 * * *$ & $-2.31 * * *$ & \\
\hline & $(0.13)$ & $(0.13)$ & & $(0.12)$ & $(0.13)$ & \\
\hline \multirow[t]{2}{*}{ Unrelated Males } & $-0.56 * *$ & $-0.61 * *$ & & $-0.80 * * *$ & $-0.85 * * *$ & \\
\hline & $(0.28)$ & $(0.29)$ & & $(0.25)$ & $(0.25)$ & \\
\hline \multirow[t]{2}{*}{ Unrelated Females } & $-1.40 * * *$ & $-1.49 * * *$ & & $-1.40 * * *$ & $-1.46 * * *$ & \\
\hline & $(0.14)$ & $(0.14)$ & & $(0.13)$ & $(0.14)$ & \\
\hline \multirow[t]{2}{*}{ Constant } & $3.68 * * *$ & $4.73 * * *$ & 1.33 & $3.11 * * *$ & $3.20 * * *$ & $2.57 * * *$ \\
\hline & $(0.62)$ & $(0.74)$ & $(1.01)$ & $(0.16)$ & $(0.19)$ & $(0.31)$ \\
\hline Observations & 55,628 & 39,242 & 16,386 & 55,628 & 39,242 & 16,386 \\
\hline R-squared & 0.06 & 0.07 & 0.04 & 0.06 & 0.07 & 0.03 \\
\hline Fixed Effects & H'hold & H'hold & H'hold & H'hold-Year & H'hold-Year & H'hold-Year \\
\hline F-Stat. test1 & 0.95 & 1.57 & & 1.42 & 2.10 & \\
\hline$p$ value & 0.39 & 0.21 & & 0.00 & 0.12 & \\
\hline F-Stat. test2 & 21.17 & 18.35 & & 30.69 & 25.05 & \\
\hline$p$ value & 0.00 & 0.00 & & 0.24 & 0.00 & \\
\hline F-Stat. test3 & 83.81 & 72.04 & 27.01 & 87.16 & 77.15 & 29.22 \\
\hline$p$ value & 0.00 & 0.00 & 0.00 & 0.00 & 0.00 & 0.00 \\
\hline
\end{tabular}

Source: Authors calculations using data from the Ministry of Agriculture of Burkina Faso.

Notes: ${ }^{* *}$ significant at the 1 percent level, ${ }^{* *}$ significant at the 5 percent level and ${ }^{*}$ significant at the 10 percent level. Robust standard errors, clustered at the village level.

The dependent variable is natural log of each household member contribution on collective plots. Columns 1 and 4 show the estimates for the pooled sample. Columns 2 and 5 show the estimates for extended family households, and columns 4 and 6 show the estimates for nuclear family households. Columns 1-3 control for household fixed effects, and columns 4-6 control for household-year fixed effects. All regressions control for worker's age and age squared, education level and the individual's private plot size (not shown). In addition, columns 1-3 include the size of the collective plot, household size and composition and time trend (not shown). F-Stat. test1 is short for an F-test that the coefficients on son and other males are equal. F-Stat. test2 is short for an F-test that the coefficients on daughter and other females are equal. F-Stat. test3 is short for an F-test that the coefficients on all nuclear members (spouse, son, daughter) are all equal. 
Table 8: Effects of Rainfall on Household Income

\begin{tabular}{|c|c|c|c|c|}
\hline & \multicolumn{4}{|c|}{ Dependent Variable: Natural Log of Household Income } \\
\hline & (1) & $(2)$ & (3) & (4) \\
\hline \multicolumn{5}{|c|}{ Rainfall deviation from long run average interacted with farm area of type: } \\
\hline \multirow{2}{*}{ low ground-collective plots } & $0.053 * *$ & $0.069 * *$ & & \\
\hline & $(0.025)$ & (0.027) & & \\
\hline \multirow[t]{2}{*}{ sloping ground-collective plots } & 0.005 & 0.008 & & \\
\hline & $(0.016)$ & $(0.016)$ & & \\
\hline \multirow[t]{2}{*}{ location "brousse"-collective plots } & $0.159 * * *$ & $0.152 * * *$ & & \\
\hline & $(0.011)$ & $(0.010)$ & & \\
\hline \multirow[t]{2}{*}{ location "campement"-collective plots } & $0.123 * * *$ & $0.120 * * *$ & & \\
\hline & $(0.020)$ & $(0.021)$ & & \\
\hline \multirow[t]{2}{*}{ low ground-male plots } & 0.044 & & $0.091 *$ & \\
\hline & $(0.063)$ & & $(0.049)$ & \\
\hline \multirow[t]{2}{*}{ sloping ground-male plots } & $0.113^{* *}$ & & 0.078 & \\
\hline & $(0.056)$ & & $(0.058)$ & \\
\hline \multirow[t]{2}{*}{ location "brousse"-male plots } & $0.150 * * *$ & & $0.112 * * *$ & \\
\hline & $(0.020)$ & & $(0.025)$ & \\
\hline \multirow[t]{2}{*}{ location "campement"-male plots } & 0.038 & & -0.009 & \\
\hline & $(0.027)$ & & $(0.031)$ & \\
\hline \multirow[t]{2}{*}{ low ground-female plots } & $0.163 * *$ & & & $0.124^{*}$ \\
\hline & $(0.074)$ & & & $(0.067)$ \\
\hline \multirow[t]{2}{*}{ sloping ground-female plots } & $0.146^{*}$ & & & 0.122 \\
\hline & $(0.086)$ & & & $(0.091)$ \\
\hline \multirow[t]{2}{*}{ location "brousse"-female plots } & $0.152 * * *$ & & & $0.237 * * *$ \\
\hline & $(0.028)$ & & & $(0.028)$ \\
\hline \multirow[t]{2}{*}{ location "campement"-female plots } & $0.226 * * *$ & & & $0.268 * * *$ \\
\hline & $(0.080)$ & & & $(0.079)$ \\
\hline Observations & 12,958 & 12,958 & 12,958 & 12,958 \\
\hline F-Stat. test excluded instruments & 31.16 & 61.10 & 7.60 & 28.12 \\
\hline p value & 0.00 & 0.00 & 0.00 & 0.00 \\
\hline
\end{tabular}

Source: Authors calculations using data from the Ministry of Agriculture of Burkina Faso.

Notes: ${ }^{* *}$ significant at the 1 percent level, ${ }^{* *}$ significant at the 5 percent level and ${ }^{*}$ significant at the 10 percent level. Robust standard errors, clustered at the village level. The dependent variable is the natural log of household's total income. In column 1 , the instruments consist of rainfall deviation interacted with the characteristics of all household plots. In columns 2-4, the instruments consist of rainfall deviation interacted with the characteristics of collective plots, the characteristics of male private plots, and the characteristics of female private plots, respectively. The regressions control for household fixed effects and village-year-fixed effects. Other covariates (not shown) are household demographic characteristics, age and gender of the household head. We report Fstatistics for the excluded instruments in each column. 
Table 9: Household Consumption Responses to Income Shocks

Panel A: Effects of Plot Specific Income Shocks on Household Total Food Consumption

\begin{tabular}{|c|c|c|c|c|c|c|}
\hline & \multicolumn{6}{|c|}{ Dependent Variable: Log of Total Food Consumption } \\
\hline & $\begin{array}{c}\text { All H'holds } \\
\text { (1) }\end{array}$ & $\begin{array}{c}\text { Nuclear } \\
(2)\end{array}$ & $\begin{array}{c}\text { Extended } \\
(3)\end{array}$ & $\begin{array}{c}\text { All H'holds } \\
\text { (4) }\end{array}$ & $\begin{array}{c}\text { Nuclear } \\
\text { (5) }\end{array}$ & $\begin{array}{c}\text { Extended } \\
(6)\end{array}$ \\
\hline \multirow[t]{2}{*}{ log total income-all plots IV } & $0.227^{* * *}$ & $0.414 * * *$ & $0.178 * * *$ & & & \\
\hline & $(0.045)$ & $(0.128)$ & $(0.067)$ & & & \\
\hline \multirow[t]{2}{*}{ log total income-collective plots IV } & & & & $0.223 * * *$ & $0.582 * * *$ & 0.097 \\
\hline & & & & $(0.053)$ & $(0.160)$ & $(0.072)$ \\
\hline \multirow[t]{2}{*}{ log total income-male private plots IV } & & & & $0.452 * * *$ & $1.313^{* *}$ & 0.179 \\
\hline & & & & $(0.166)$ & $(0.518)$ & $(0.210)$ \\
\hline log total income-female private plots IV & & & & 0.158 & -0.042 & $0.337^{* *}$ \\
\hline Chi-sq (1) & & & 8.01 & & & \\
\hline Chi-sq (1) p-val & & & 0.00 & & & \\
\hline F-Stat. & & & & 1.04 & 2.94 & 1.11 \\
\hline $\mathrm{p}$ value & & & & 0.35 & 0.05 & 0.33 \\
\hline Hansen J-stat & 3.197 & 0.771 & 2.309 & & & \\
\hline Chi-sq (3) p-val & 0.362 & 0.856 & 0.511 & & & \\
\hline Wald statistic & & & & 17.60 & 4.10 & 11.80 \\
\hline$p$ value & & & & 0.01 & 0.66 & 0.07 \\
\hline
\end{tabular}

Panel B: Effects of Plot Specific Income Shocks on Different Categories of Household Food Consumption

\begin{tabular}{|c|c|c|c|c|c|c|c|c|c|}
\hline Dependent Variable is log of: & cereals & cereals & cereals & $\begin{array}{c}\text { pulses \& } \\
\text { vegetables }\end{array}$ & $\begin{array}{c}\text { pulses \& } \\
\text { vegetables }\end{array}$ & $\begin{array}{c}\text { pulses \& } \\
\text { vegetables } \\
\end{array}$ & other food & $\begin{array}{l}\text { other } \\
\text { food }\end{array}$ & $\begin{array}{l}\text { other } \\
\text { food }\end{array}$ \\
\hline & $\begin{array}{c}\text { All H'holds } \\
\text { (1) }\end{array}$ & $\begin{array}{c}\text { Nuclear } \\
(2)\end{array}$ & $\begin{array}{c}\text { Extended } \\
\text { (3) }\end{array}$ & $\begin{array}{c}\text { All H'holds } \\
\text { (4) }\end{array}$ & $\begin{array}{c}\text { Nuclear } \\
(5)\end{array}$ & $\begin{array}{c}\text { Extended } \\
(6)\end{array}$ & $\begin{array}{c}\text { All H'holds } \\
\text { (7) }\end{array}$ & $\begin{array}{c}\text { Nuclear } \\
(8)\end{array}$ & $\begin{array}{c}\text { Extended } \\
\text { (9) }\end{array}$ \\
\hline log total income-collective plots IV & $\begin{array}{c}0.290 * * * \\
(0.087)\end{array}$ & $\begin{array}{c}0.696 * * * \\
(0.233)\end{array}$ & $\begin{array}{l}0.189 * \\
(0.108)\end{array}$ & $\begin{array}{c}0.661 * * * \\
(0.190)\end{array}$ & $\begin{array}{c}0.844 \\
(0.651)\end{array}$ & $\begin{array}{l}0.446^{*} \\
(0.257)\end{array}$ & $\begin{array}{c}0.289 \\
(0.262)\end{array}$ & $\begin{array}{c}0.645 \\
(1.073)\end{array}$ & $\begin{array}{c}0.318 \\
(0.341)\end{array}$ \\
\hline log total income-male private plots IV & $\begin{array}{l}0.539 * \\
(0.285)\end{array}$ & $\begin{array}{c}0.743 \\
(0.555)\end{array}$ & $\begin{array}{c}0.075 \\
(0.337)\end{array}$ & $\begin{array}{c}1.628 * * * \\
(0.511)\end{array}$ & $\begin{array}{c}2.760 * * \\
(1.395)\end{array}$ & $\begin{array}{c}0.663 \\
(0.711)\end{array}$ & $\begin{array}{c}0.788 \\
(0.670)\end{array}$ & $\begin{array}{l}3.809 * \\
(2.201)\end{array}$ & $\begin{array}{c}1.471 \\
(0.994)\end{array}$ \\
\hline log total income-female private plots IV & $\begin{array}{c}0.031 \\
(0.236)\end{array}$ & $\begin{array}{l}-0.695 \\
(1.011)\end{array}$ & $\begin{array}{c}0.193 \\
(0.222)\end{array}$ & $\begin{array}{c}0.510 \\
(0.321)\end{array}$ & $\begin{array}{c}0.125 \\
(1.202)\end{array}$ & $\begin{array}{c}0.605 \\
(0.491)\end{array}$ & $\begin{array}{l}0.884^{*} \\
(0.497)\end{array}$ & $\begin{array}{c}1.707 \\
(1.394)\end{array}$ & $\begin{array}{c}0.396 \\
(0.724)\end{array}$ \\
\hline
\end{tabular}

Source: Authors calculations using data from the Ministry of Agriculture of Burkina Faso.

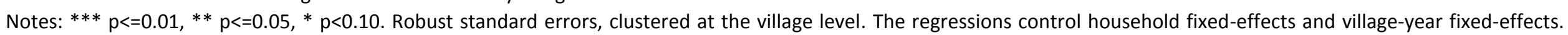

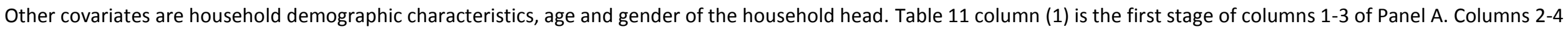

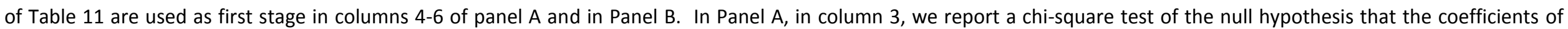

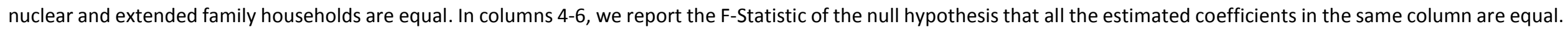

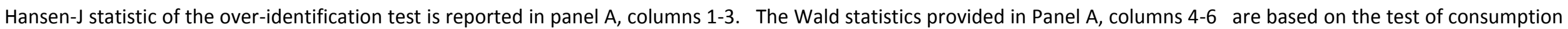
efficiency using equation (19). 
Table 10: Test of Intra-household Risk-Sharing based on Child Anthropometric Data

\begin{tabular}{|c|c|c|c|c|c|c|}
\hline \multirow[b]{2}{*}{ VARIABLES } & \multicolumn{6}{|c|}{ Dependent Variable: Z-Score of Child Mid-Upper-Arm Circumference } \\
\hline & $\begin{array}{c}\text { All H'holds } \\
\text { (1) }\end{array}$ & $\begin{array}{c}\text { Nuclear } \\
(2)\end{array}$ & $\begin{array}{c}\text { Extended } \\
\text { (3) }\end{array}$ & $\begin{array}{c}\text { All } H^{\prime} \text { holds } \\
\text { (4) }\end{array}$ & $\begin{array}{c}\text { Nuclear } \\
\text { (5) }\end{array}$ & $\begin{array}{c}\text { Extended } \\
(6)\end{array}$ \\
\hline log of mother's crop income & $\begin{array}{l}0.009 * \\
(0.005)\end{array}$ & $\begin{array}{c}0.002 \\
(0.013)\end{array}$ & $\begin{array}{c}0.013 * * * \\
(0.005)\end{array}$ & & & \\
\hline log of mother's cons. expend. & & & & $\begin{array}{l}0.019 * \\
(0.011)\end{array}$ & $\begin{array}{c}0.010 \\
(0.030)\end{array}$ & $\begin{array}{c}0.028 * * * \\
(0.011)\end{array}$ \\
\hline child is female & $\begin{array}{c}0.072 * * * \\
(0.015)\end{array}$ & $\begin{array}{c}0.115^{* * *} \\
(0.028)\end{array}$ & $\begin{array}{c}0.057^{* * *} \\
(0.018)\end{array}$ & $\begin{array}{c}0.072 * * * \\
(0.015)\end{array}$ & $\begin{array}{c}0.115^{* * *} \\
(0.028)\end{array}$ & $\begin{array}{c}0.057^{* * *} \\
(0.018)\end{array}$ \\
\hline Observations & 38,777 & 12,037 & 25,902 & 38,777 & 12,037 & 25,902 \\
\hline R-squared & 0.048 & 0.035 & 0.055 & 0.046 & 0.034 & 0.049 \\
\hline
\end{tabular}

Source: Authors calculations using data from the Ministry of Agriculture of Burkina Faso.

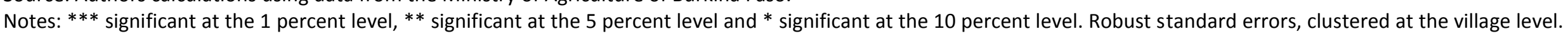

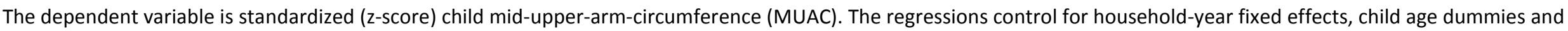
the month in which the measure was taken. There are two observations per child per year, the first taken in July, the second in December. 
Table 11: Estimates of Yields for Extended and Nuclear Family Households with Homogenous Sub-Samples

\begin{tabular}{|c|c|c|c|c|c|c|c|c|c|}
\hline \multirow[b]{2}{*}{ VARIABLES } & \multicolumn{9}{|c|}{ Dependent Variable: Ln(Plot Yield in Value/Hectare) } \\
\hline & $\begin{array}{c}\text { All } H^{\prime} \text { holds } \\
\text { (1) }\end{array}$ & $\begin{array}{c}\text { Extended } \\
\text { (2) }\end{array}$ & $\begin{array}{l}\text { Nuclear } \\
\text { (3) }\end{array}$ & $\begin{array}{c}\text { All H'holds } \\
\text { (4) }\end{array}$ & $\begin{array}{c}\text { Extended } \\
\text { (5) }\end{array}$ & $\begin{array}{c}\text { Nuclear } \\
\text { (6) }\end{array}$ & $\begin{array}{l}\text { All H'holds } \\
\text { (7) }\end{array}$ & $\begin{array}{c}\text { Extended } \\
\text { (8) }\end{array}$ & $\begin{array}{c}\text { Nuclear } \\
\text { (9) }\end{array}$ \\
\hline \multicolumn{10}{|c|}{ Plot Type: ('collective plots' excluded) } \\
\hline Male Private & $\begin{array}{c}-0.24 * * * \\
(0.04)\end{array}$ & $\begin{array}{c}-0.27^{* * *} \\
(0.04)\end{array}$ & $\begin{array}{l}-0.10 \\
(0.08)\end{array}$ & $\begin{array}{c}-0.24^{* * *} \\
(0.03)\end{array}$ & $\begin{array}{c}-0.26^{* * *} \\
(0.03)\end{array}$ & $\begin{array}{c}-0.18^{* * *} \\
(0.05)\end{array}$ & $\begin{array}{c}-0.22^{* * *} \\
(0.04)\end{array}$ & $\begin{array}{c}-0.27^{* * *} \\
(0.05)\end{array}$ & $\begin{array}{c}-0.15^{* * *} \\
(0.05)\end{array}$ \\
\hline Female Private & $\begin{array}{c}-0.42 * * * \\
(0.03)\end{array}$ & $\begin{array}{c}-0.47^{* * *} \\
(0.04)\end{array}$ & $\begin{array}{c}-0.29 * * * \\
(0.05)\end{array}$ & $\begin{array}{c}-0.47^{* * *} \\
(0.02)\end{array}$ & $\begin{array}{c}-0.53^{* * *} \\
(0.03)\end{array}$ & $\begin{array}{c}-0.36^{* * *} \\
(0.04)\end{array}$ & $\begin{array}{c}-0.41^{* * *} \\
(0.03)\end{array}$ & $\begin{array}{c}-0.47^{* * *} \\
(0.04)\end{array}$ & $\begin{array}{c}-0.34^{* * *} \\
(0.03)\end{array}$ \\
\hline Plot Owner Age & $\begin{array}{c}0.02^{* * *} \\
(0.00)\end{array}$ & $\begin{array}{c}0.02^{* * *} \\
(0.00)\end{array}$ & $\begin{array}{c}0.02^{* *} \\
(0.01)\end{array}$ & $\begin{array}{c}0.02^{* * *} \\
(0.00)\end{array}$ & $\begin{array}{c}0.02^{* * *} \\
(0.00)\end{array}$ & $\begin{array}{c}0.04 * * * \\
(0.01)\end{array}$ & $\begin{array}{c}0.02 * * * \\
(0.00)\end{array}$ & $\begin{array}{c}0.02^{* * *} \\
(0.00)\end{array}$ & $\begin{array}{c}0.03^{* * *} \\
(0.00)\end{array}$ \\
\hline Age Squared & $\begin{array}{c}-0.02 * * * \\
(0.00)\end{array}$ & $\begin{array}{c}-0.02 * * * \\
(0.00)\end{array}$ & $\begin{array}{c}-0.01 \\
(0.01)\end{array}$ & $\begin{array}{c}-0.02 * * * \\
(0.00)\end{array}$ & $\begin{array}{c}-0.02 * * * \\
(0.00)\end{array}$ & $\begin{array}{c}-0.04 * * * \\
(0.01)\end{array}$ & $\begin{array}{c}-0.02 * * * \\
(0.00)\end{array}$ & $\begin{array}{c}-0.02 * * * \\
(0.00)\end{array}$ & $\begin{array}{c}-0.02 * * * \\
(0.00)\end{array}$ \\
\hline Constant & $\begin{array}{c}12.31^{* * *} \\
(0.10)\end{array}$ & $\begin{array}{c}12.36^{* * *} \\
(0.11)\end{array}$ & $\begin{array}{c}12.12^{* * *} \\
(0.23)\end{array}$ & $\begin{array}{c}12.34^{* * *} \\
(0.07)\end{array}$ & $\begin{array}{c}12.47^{* * *} \\
(0.08)\end{array}$ & $\begin{array}{c}11.95^{* * *} \\
(0.15)\end{array}$ & $\begin{array}{c}12.29 * * * \\
(0.09)\end{array}$ & $\begin{array}{c}12.46^{* * *} \\
(0.12)\end{array}$ & $\begin{array}{c}12.11^{* * *} \\
(0.12)\end{array}$ \\
\hline Observations & 35,873 & 22,344 & 13,529 & 68,293 & 43,260 & 25,033 & 47,835 & 20,380 & 27,455 \\
\hline R-squared & 0.36 & 0.37 & 0.36 & 0.38 & 0.38 & 0.38 & 0.37 & 0.36 & 0.38 \\
\hline specification robust to & monogamy & monogamy & monogamy & head age & head age & head age & h'hold size & h'hold size & h'hold size \\
\hline F-St. test Male_Plot $=$ Female_Plot $=0$ & 96.56 & 82.95 & 18.08 & 225.8 & 220.6 & 49.07 & 122.1 & 79.11 & 55.70 \\
\hline$p$ value & 0.00 & 0.00 & 0.00 & 0.00 & 0.00 & 0.00 & 0.00 & 0.00 & 0.00 \\
\hline
\end{tabular}

Source: Authors calculations using data from the Ministry of Agriculture of Burkina Faso.

Notes: ${ }^{* *}$ significant at the 1 percent level, ${ }^{* *}$ significant at the 5 percent level and $*$ significant at the 10 percent level. Robust standard errors, clustered at the village level. The dependent variable is natural log of plot yield measured in the local currency per hectare. Columns 1-3 show estimates for monogamous household heads. In columns 4-6, age of household head is the same on average for nuclear and extended family households. In columns 7-9, nuclear and extended family household have the same size on average. Columns 1, 4 and 7 include all households. Columns 2, 5, and 8 include extended family households. Columns 3,6 and 9 include nuclear family households. The regressions control for household-crop-year fixed effects. Dummy variables representing the plot manager education level and dummy variables representing plot size by deciles, plot location and topography are included in the regressions but not shown. 
Table 12: Tests for Consumption Efficiency using Homogenous Subsamples

\begin{tabular}{|c|c|c|c|c|c|c|c|c|c|}
\hline & \multicolumn{3}{|c|}{ Monogamous Households } & \multicolumn{3}{|c|}{ Similar Size Households } & \multicolumn{3}{|c|}{ Similar Head Age Households } \\
\hline & All & Nuclear & Extended & All & Nuclear & Extended & All & Nuclear & Extended \\
\hline \multicolumn{10}{|c|}{ Test of Consumption Efficiency } \\
\hline Wald statistic & 11.51 & 1.80 & 7.34 & 13.18 & 2.71 & 17.60 & 14.86 & 5.64 & 9.15 \\
\hline prob & 0.07 & 0.94 & 0.29 & 0.04 & 0.84 & 0.01 & 0.02 & 0.46 & 0.17 \\
\hline
\end{tabular}

Source: Authors calculations using data from the Ministry of Agriculture of Burkina Faso.

Notes: The tests use the coefficients on regressions similar to those reported in Table 13, but estimated for each subsample.

Regressions results are available from the authors. 
Table 13: Land Inherited by Household Head and Household Structure

\begin{tabular}{|c|c|c|c|c|c|c|c|c|c|c|c|c|c|}
\hline \multirow[b]{2}{*}{ VARIABLES } & \multicolumn{13}{|c|}{ Binary Dependent Variable: (Nuclear Family Household $=1$ ) } \\
\hline & (1) & (2) & (3) & (4) & (5) & (6) & (7) & (8) & (9) & (10) & (11) & (12) & (13) \\
\hline & & - & & & & & & & & & & & \\
\hline land inherited by head & $\begin{array}{r}-0.024^{* * *} \\
(0.003)\end{array}$ & $\begin{array}{r}0.024 * * * \\
(0.003)\end{array}$ & $\begin{array}{r}-0.024^{* * *} \\
(0.003)\end{array}$ & $\begin{array}{r}-0.038^{* * *} \\
(0.004)\end{array}$ & $\begin{array}{r}-0.034^{* * *} \\
(0.004)\end{array}$ & $\begin{array}{r}-0.034^{* * *} \\
(0.004)\end{array}$ & $\begin{array}{r}-0.043^{* * *} \\
(0.002)\end{array}$ & $\begin{array}{r}-0.046^{* * *} \\
(0.003)\end{array}$ & $\begin{array}{r}-0.047^{* * *} \\
(0.003)\end{array}$ & $\begin{array}{r}-0.023^{* * *} \\
(0.003)\end{array}$ & $\begin{array}{r}-0.039 * * * \\
(0.003)\end{array}$ & $\begin{array}{r}-0.021^{* * *} \\
(0.003)\end{array}$ & $\begin{array}{r}-0.040^{* * *} \\
(0.003)\end{array}$ \\
\hline Inherited land squared & & & & & & & $\begin{array}{r}0.001^{* * *} \\
(0.000)\end{array}$ & $\begin{array}{r}0.001 * * * \\
(0.000)\end{array}$ & $\begin{array}{r}0.001^{* * *} \\
(0.000)\end{array}$ & & $\begin{array}{r}0.001^{* * *} \\
(0.000)\end{array}$ & & $\begin{array}{r}0.001^{* * *} \\
(0.000)\end{array}$ \\
\hline other h'hold farm land & $\begin{array}{r}-0.035^{* * *} \\
(0.003)\end{array}$ & $\begin{array}{r}- \\
0.037^{* * *} \\
(0.004)\end{array}$ & $\begin{array}{r}-0.039 * * * \\
(0.004)\end{array}$ & & & & $\begin{array}{r}-0.037 * * * \\
(0.003)\end{array}$ & $\begin{array}{r}-0.040 * * * \\
(0.004)\end{array}$ & $\begin{array}{r}-0.042^{* * *} \\
(0.004)\end{array}$ & & & & \\
\hline land per capita & & 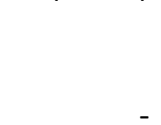 & & $\begin{array}{r}0.286 * * * \\
(0.025)\end{array}$ & $\begin{array}{r}0.272^{* * *} \\
(0.024)\end{array}$ & $\begin{array}{r}0.279 * * * \\
(0.025)\end{array}$ & & & & & & & \\
\hline head is female & $\begin{array}{r}-0.010 * * * \\
(0.001)\end{array}$ & $\begin{array}{r}0.009 * * * \\
(0.002)\end{array}$ & $\begin{array}{r}-0.009 * * * \\
(0.002)\end{array}$ & $\begin{array}{r}-0.011^{* * *} \\
(0.001)\end{array}$ & $\begin{array}{r}-0.010 * * * \\
(0.002)\end{array}$ & $\begin{array}{r}-0.011 * * * \\
(0.002)\end{array}$ & $\begin{array}{r}-0.010^{* * *} \\
(0.002)\end{array}$ & $\begin{array}{r}-0.009 * * * \\
(0.002)\end{array}$ & $\begin{array}{r}-0.010 * * * \\
(0.002)\end{array}$ & $\begin{array}{r}-0.011^{* * *} \\
(0.001)\end{array}$ & $\begin{array}{r}-0.010^{* * *} \\
(0.002)\end{array}$ & $\begin{array}{r}-0.011^{* * *} \\
(0.002)\end{array}$ & $\begin{array}{r}-0.011^{* * *} \\
(0.002)\end{array}$ \\
\hline year 2011 & $\begin{array}{r}0.037^{* * *} \\
(0.010)\end{array}$ & $\begin{array}{r}0.040^{* * *} \\
(0.010)\end{array}$ & & $\begin{array}{r}0.057^{* * *} \\
(0.010)\end{array}$ & $\begin{array}{r}0.060^{* * *} \\
(0.010)\end{array}$ & & $\begin{array}{r}0.029 * * * \\
(0.010)\end{array}$ & $\begin{array}{r}0.031^{* * *} \\
(0.010)\end{array}$ & & $\begin{array}{r}0.049 * * * \\
(0.010)\end{array}$ & $\begin{array}{r}0.046^{* * *} \\
(0.010)\end{array}$ & & \\
\hline year 2012 & $\begin{array}{l}0.024^{*} \\
(0.014)\end{array}$ & $\begin{array}{r}0.011 \\
(0.014)\end{array}$ & & $\begin{array}{r}0.041^{* * *} \\
(0.014)\end{array}$ & $\begin{array}{r}0.032^{* *} \\
(0.013)\end{array}$ & & $\begin{array}{r}0.019 \\
(0.014)\end{array}$ & $\begin{array}{r}0.004 \\
(0.014)\end{array}$ & & $\begin{array}{r}0.033^{* *} \\
(0.014)\end{array}$ & $\begin{array}{r}0.017 \\
(0.014)\end{array}$ & & \\
\hline Constant & $\begin{array}{r}0.522 * * * \\
(0.138)\end{array}$ & $\begin{array}{r}0.318^{* *} \\
(0.142)\end{array}$ & $\begin{array}{r}0.552^{* * *} \\
(0.012)\end{array}$ & $\begin{array}{r}0.176 \\
(0.134)\end{array}$ & $\begin{array}{r}0.180 \\
(0.142)\end{array}$ & $\begin{array}{r}0.446^{* * *} \\
(0.012)\end{array}$ & $\begin{array}{r}0.679 * * * \\
(0.135)\end{array}$ & $\begin{array}{r}0.398^{* * *} \\
(0.140)\end{array}$ & $\begin{array}{r}0.593 * * * \\
(0.011)\end{array}$ & $\begin{array}{r}0.403^{* * *} \\
(0.137)\end{array}$ & $\begin{array}{r}0.333^{* *} \\
(0.141)\end{array}$ & $\begin{array}{r}0.526 * * * \\
(0.010)\end{array}$ & $\begin{array}{r}0.559 * * * \\
(0.010)\end{array}$ \\
\hline Observations & 13,176 & 13,176 & 13,176 & 13,176 & 13,176 & 13,176 & 13,176 & 13,176 & 13,176 & 13,176 & 13,176 & 13,176 & 13,176 \\
\hline R-squared & 0.086 & 0.067 & 0.066 & 0.089 & 0.067 & 0.066 & 0.097 & 0.080 & 0.079 & 0.069 & 0.059 & 0.048 & 0.058 \\
\hline Village fixed effects & No & yes & yes & No & yes & yes & No & yes & yes & No & yes & yes & yes \\
\hline Village-year fixed effects & No & no & yes & No & no & yes & No & no & yes & No & no & yes & yes \\
\hline
\end{tabular}

Source: Authors calculations using data from the Ministry of Agriculture of Burkina Faso.

Notes: ${ }^{* *}$ significant at the 1 percent level, ${ }^{* *}$ significant at the 5 percent level and ${ }^{*}$ significant at the 10 percent level. Robust standard errors, clustered at the village level. The dependent variable is one for nuclear family households and zero for extended family households. The regressions also control for household demographic characteristics (based on the nuclear family members) and head age and gender. Columns 1-2, 4-5, 7-8 and 10-11 also control for village level prices. 
Table 14: Variance of Long-run Income Shocks and Household Structure

\begin{tabular}{|c|c|c|c|c|c|c|}
\hline \multirow[b]{2}{*}{ VARIABLES } & \multicolumn{6}{|c|}{ Binary Dependent Variable: (Nuclear Family Household $=1$ ) } \\
\hline & $(1)$ & $(2)$ & (3) & (4) & $(5)$ & $(6)$ \\
\hline variance of income shocks & $\begin{array}{c}-0.115^{* * *} \\
(0.016)\end{array}$ & $\begin{array}{c}-0.116^{* * *} \\
(0.018)\end{array}$ & $\begin{array}{c}-0.115^{* * *} \\
(0.017)\end{array}$ & $\begin{array}{c}-0.116^{* * *} \\
(0.019)\end{array}$ & $\begin{array}{c}-0.115^{* * *} \\
(0.016)\end{array}$ & $\begin{array}{c}-0.116 * * * \\
(0.017)\end{array}$ \\
\hline current rainfall deviation & & & & & $\begin{array}{c}0.010 \\
(0.007)\end{array}$ & $\begin{array}{c}0.010 \\
(0.007)\end{array}$ \\
\hline head is female & $\begin{array}{c}-0.056^{* *} \\
(0.027)\end{array}$ & $\begin{array}{l}-0.054^{*} \\
(0.029)\end{array}$ & $\begin{array}{c}-0.056^{* *} \\
(0.027)\end{array}$ & $\begin{array}{l}-0.055^{*} \\
(0.029)\end{array}$ & $\begin{array}{c}-0.056^{* *} \\
(0.027)\end{array}$ & $\begin{array}{c}-0.056^{* *} \\
(0.027)\end{array}$ \\
\hline year 2011 & $\begin{array}{c}0.059 * * * \\
(0.010)\end{array}$ & & $\begin{array}{c}0.059 * * * \\
(0.010)\end{array}$ & & $\begin{array}{c}0.070 * * * \\
(0.012)\end{array}$ & $\begin{array}{c}0.070 * * * \\
(0.012)\end{array}$ \\
\hline year 2012 & $\begin{array}{c}0.028^{* *} \\
(0.014)\end{array}$ & & $\begin{array}{c}0.028^{* *} \\
(0.014)\end{array}$ & & $\begin{array}{c}0.022 \\
(0.015)\end{array}$ & $\begin{array}{c}0.021 \\
(0.015)\end{array}$ \\
\hline Constant & $\begin{array}{l}0.259 * \\
(0.153)\end{array}$ & $\begin{array}{c}0.510 * * * \\
(0.011)\end{array}$ & $\begin{array}{l}0.259 * \\
(0.153)\end{array}$ & $\begin{array}{c}0.509 * * * \\
(0.011)\end{array}$ & $\begin{array}{c}0.158 \\
(0.170)\end{array}$ & $\begin{array}{c}0.157 \\
(0.170)\end{array}$ \\
\hline Observations & 12,568 & 12,568 & 12,568 & 12,568 & 12,568 & 12,568 \\
\hline R-squared & 0.208 & 0.273 & 0.208 & 0.273 & 0.208 & 0.208 \\
\hline village fixed effects & yes & yes & yes & yes & yes & yes \\
\hline $\begin{array}{l}\text { village-year fixed effects } \\
\text { households fixed effects in first }\end{array}$ & no & yes & no & yes & no & no \\
\hline $\begin{array}{l}\text { stage } \\
\text { village-year fixed effects in first }\end{array}$ & yes & yes & yes & yes & yes & yes \\
\hline stage & no & no & yes & yes & no & yes \\
\hline current rainfall & no & no & no & no & yes & yes \\
\hline
\end{tabular}

Source: Authors calculations using data from the Ministry of Agriculture of Burkina Faso.

Notes: ${ }^{* *}$ significant at the 1 percent level, ${ }^{* *}$ significant at the 5 percent level and ${ }^{*}$ significant at the 10 percent level. Robust standard errors, clustered at the village level. The dependent variable is one for nuclear family households and zero for extended family households. The regressions also control for household demographic characteristics (based on the nuclear family members) and head age and gender. Columns 1-2, 4-5, 7-8 and 10-11 also control for village level prices. 